Michael Stolz

\title{
Spirituelle Artes-Auslegung
}

Das Beispiel der >Predigt vom heiligen Geist< (15. Jh.). Mit einer Textedition.

Die deutsche Predigt des Spätmittelalters betreibt nicht nur seelsorgerische Unterweisung, sondern fungiert immer wieder auch als Instrument gelehrter Wissensvermittlung. Im Predigtwerk Meister Eckharts findet der Rekurs auf philosophische und wissenschaftliche Inhalte einen in der Volkssprache selten erreichten Höhepunkt. ${ }^{1}$ Doch gibt es in der homiletischen Praxis weitere, wenn auch weniger spektakuläre Beispiele der Applikation und Transformation von Wissen. Diese Zeugnisse verdienen nicht zuletzt deshalb Beachtung, weil sich hier in Blickrichtung auf die deutsche Predigt Umwandlungsprozesse beobachten lassen, wie etwa der Eingang gelehrter Schriftlichkeit in eine mündlichen Gebrauchskontexten verpflichtete Gattung oder die Einwirkung lateinischer Diskursstrategien auf einen volkssprachlichen Artikulationsbereich.

Ein illustratives Beispiel liefert ein anonymer, bislang unveröffentlichter Text des 15. Jahrhunderts, der in den Handschriften als >Predigt vom heiligen Geist< betitelt wird. Es handelt sich hierbei um eine geistliche Auslegung der Artes liberales, der sprachlichen und mathematischen Studienfächer des mittelalterlichen Unterrichtswesens. Die sieben freien Künste werden gemäß einem sensus spiritualis interpretiert und liefern mit ihren fachlichen Inhalten den Ausgangspunkt für moralisierende Anweisungen.

Das Verfahren einer solchen Adaptation von Wissen ist dem Mittelalter durchaus vertraut. Die Geschichte der spirituellen Ausdeutung von Artes-Wissen kann an dieser Stelle nicht im einzelnen nachgezeichnet werden, doch sei wenigstens auf einige herausragende Beispiele verwiesen. Eine geistlich-moralische Interpretation der freien Künste findet sich etwa im Umkreis der sogenannten $>$ Schule von Chartres $<$ Sie erscheint in einem Traktat aus dem 12. Jahrhundert, der fälschlicherweise Johannes von Salisbury zugeschrieben wurde und den Titel >De septem septenis< trägt. ${ }^{2}$ Möglicherweise hat diese Schrift $>$ von der Siebenzahl< auf den friulischen Kleriker Thomasins von Zerklære gewirkt, der in seinem um 1215 entstandenen >Welschen Gast< ebenfalls eine Moralisierung der Artes vornimmt. ${ }^{3}$ Im Spätmittelalter häufen sich dann Abhandlungen mit

\footnotetext{
${ }^{1}$ Vgl. dazu die Beiträge von WALter HaUG und Freimut LöSER im vorliegenden Band.

2 Abdruck in PL 199, Sp. 945-964.

${ }^{3}$ Vgl. Der Wälsche Gast des Thomasin von Zirclaria, hg. von HeINRICH RÜCKERT, mit einer Einleitung und einem Register von FRIEDRICH NEUMANN (Deutsche Neudrucke. Reihe: Texte des Mittelalters $=$ Nachdruck der Ausgabe Quedlinburg/Leipzig 1852 [Bibliothek der gesammten deutschen National-Literatur 30]), Berlin 1965, Buch VII, vv. 8915-9062, S. 243-247. Zum mög-
} 
spiritueller Artes-Auslegung. Das Textmaterial ruht zum Großteil noch unerschlossen in den Bibliotheken. Ein wichtiges Beispiel liefert das sogenannte >Magisterium Christi< des Prager Gelehrten Heinrich Honover aus dem späten 14. Jahrhundert. ${ }^{4}$ In diesem lateinischen Schriftstïck tritt Christus als vorbildlicher Lehrmeister auf, erscheint als verus gramaticus, verus rhetoricus usw., der die Inhalte der einzelnen Künste geistlich ausdeutet und vorlebt. Für den deutschsprachigen Bereich sei schließlich der Dominikaner Johannes Nider genannt, der dem geistigen Milieu der sogenannten $>$ Wiener Schule< zugeordnet wird. ${ }^{5}$ Um das Jahr 1428 verfaßt Nider eine Traktatsammlung mit dem Titel $>$ Die vierundzwanzig goldenen Harfen $<$. Dieses Werk bietet die Anleitung zu einem vollkommenen religiös-asketischen Leben; es orientiert sich am Vorbild der >Collationes< des frühchristlichen Eremiten Johannes Cassianus und verrät den Einfluß Heinrich Seuses. Niders vierzehntes Kapitel (Die xiiii. harpfen) handelt von der schul der ewigen weisheit und bezieht die einzelnen Fächer des mittelalterlichen Wissenschaftssystems auf eine christliche Lebensführung. ${ }^{6}$

Die >Predigt vom heiligen Geist< ist in manchem mit Niders Abhandlung vergleichbar, auch wenn es sich um jeweils unterschiedliche Textsorten handelt und die Artes-Auslegung inhaltlich jeweils anders ausgeprägt ist. In beiden Fällen wird hier ein volkssprachlich-illiterates Zielpublikum anvisiert, in beiden Fällen lassen sich Merkmale klösterlicher Seelsorge und Reformbestrebungen sowie generell ein mystisch-asketisches Umfeld erkennen. Beide Male bewegt sich der Schwerpunkt der Überlieferung im oberdeutschen Sprachgebiet.

lichen Einfluß des Traktats >De septem septenis<vgl. ANTON E. SCHÖNBACH, Die Anfänge des deutschen Minnesangs. Eine Studie, Graz 1898, S. 46, und DANIEl Rocher, Thomasin von Zerklaere: Der Wälsche Gast (1215-1216), 2 Bde., Thèse Paris IV 1976, Lille/Paris 1977, S. 893f., 900f.

${ }^{4}$ Bekannte Handschriften: Praha, Knihovna prašké kapituly, Cod. 0. XXXVIII, fol. 1 ${ }^{\mathrm{r}}-52^{\mathrm{v}}$; Praha, Národní knihovna, Cod. IX. A. 4, fol. 196 (Fragment); Wrocław, Biblioteka uniwersytecka, Cod. I. F. 530, fol. 213 $-242^{\mathrm{v}}$; Warszawa, Biblioteka narodowa, Cod. lat. chart. Q.I. 168 (1944 verbrannt). Vgl. JOSEF TŘIŠKA, Literární činnost předhusitské university (Sbírka pramenů a př́ruček k dějinám university Karlovy 5), Praha 1967, S. 28f.; KARL-AuguST WIRTH, Die kolorierten Federzeichnungen im Cod. 2975 der Österreichischen Nationalbibliothek. Ein Beitrag zur Ikonographie der Artes Liberales im 15. Jahrhundert, Anzeiger des Germanischen Nationalmuseums 1979, S. 67-110, hier S. 90, 107f. (Anm. 154), 109 (Anm. 186); JÜRGEN STOHLMANN, Honover, Heinrich, ${ }^{2}$ VL IV, Sp. 132-137, hier Sp. 134f.

${ }^{5}$ Vgl. EugEn HiLlenbrand, Nider, Johannes OP, ${ }^{2}$ VL VI, Sp. 971-977; MARgit Brand, Studien zu Johannes Niders deutschen Schriften (Dissertationes historicae, Institutum Historicum Fratrum Praedicatorum Romae 23), Rom 1998; zur >Wiener Schule< den Überblick von THOMAS HOHMANN, Die recht gelerten maister. Bemerkungen zur Übersetzungsliteratur der Wiener Schule des Spätmittelalters, in: Die österreichische Literatur. Ihr Profil von den Anfängen im Mittelalter bis ins 18. Jahrhundert (1050-1750), hg. von Fritz PETER KNAPP u. HERBERT ZEMAN, Graz 1986, S. 349-365.

${ }^{6}$ Vgl. Ulla Williams, Schul der weisheit. Spirituelle artes-Auslegung bei Johannes Nider. Mit Edition der $>14$. Harfe<, in: Überlieferungsgeschichtliche Editionen und Studien zur deutschen Literatur des Mittelalters. Kurt Ruh zum 75. Geburtstag, hg. von KonRAD KunZE [u. a.] (TTG 31), Tübingen 1989, S. 391-424; JOHANNES NIDER, >Die vierundzwanzig goldenen Harfen<. Edition und Kommentar, hg. von Stefan Abel (Spätmittelalter, Humanismus, Reformation 60), Tübingen 2011. 
Von der $>$ Predigt vom heiligen Geist $<(P v h G)$ sind bislang sechs Überlieferungsträger, allesamt Papierhandschriften, bekannt ${ }^{7}$ (im folgenden nur die wichtigsten Angaben, ausführlichere Beschreibungen jeweils in der verzeichneten Literatur):

$\mathrm{A}=$ München, BSB, Cgm 830, fol. $187^{\mathrm{v}}-200^{\mathrm{v}}$ I + 247 Bl. (143 x $100 \mathrm{~mm})$ - ca. Mitte des 15. Jhs. - Provenienz: Augsburg, St. Ulrich und Afra - Schrift wohl von einer Hand (Bl. $\left.1^{\mathrm{r}}-222^{\mathrm{r}}\right)$ : Bastarda, einspaltig - Mundart: ostschwäbisch - Sammlung geistlicher Texte u. a. von Heinrich von Friemar ( $>$ De IV instinctibus<, dt. Bearb.), Johannes von Indersdorf, Seuse, David von Augsburg. ${ }^{8}$

$\mathrm{B}=$ Berlin, SBB-PK, mgq 1134, fol. $1^{\mathrm{r}}-11^{\mathrm{v}}$

213 Bl. (207 x $150 \mathrm{~mm}$ ) - datiert auf 1490 (fol. 201v) - Provenienz: Augsburg, Dominikanerinnen, St. Katharina, >auf dem Gries $<-$ Schrift der PvhG und des >Eucharistie-Traktats< (s. u.) von derselben Hand: Bastarda, einspaltig Mundart: bairisch - enthält u. a. >Taulers Bekehrung< und Marquards von Lindau $>$ Eucharistie-Traktat $<.{ }^{9}$

$\mathrm{G}=$ Graz, UB, Ms. 1035, fol. $335^{\mathrm{r}}-344^{\mathrm{v}}$

468 Bl. $(210$ x $150 \mathrm{~mm})-2$. Hälfte des 15. Jhs. - Provenienz: unbekannt Schrift der PvhG: Bastarda, einspaltig - Mundart: bairisch - enthält u. a. >Der Altväter und Einsiedler Rede und Lehre<, >Sprüche und Lehren der Bibel und der Heiligen $<$, Heinrichs von Friemar $>$ De IV instinctibus $<(\text { dt. Bearb. })^{10}$

\footnotetext{
${ }^{7}$ Einen ersten Hinweis auf die Predigt erhielt ich während der Vorbereitung meines Habilitationsprojekts zu Artes-liberales-Zyklen in lateinischen und deutschen Handschriften des Mittelalters durch Konsultation des Sachregisters in: Die deutschen Handschriften der Bayerischen Staatsbibliothek München. Cgm 691-867, neu beschr. von KARIN SCHNEIDER (Catalogus codicum manu scriptorum Bibliothecae Monacensis. Tomus V, Editio altera, Pars 5), Wiesbaden 1984, hier S. 750b, 755a. Aus der in diesem Katalog enthaltenen Beschreibung von zweien der Münchener Handschriften und dem dortigen Hinweis auf Thomas HoHmann, Discretio spirituum. Text und Untersuchung zur > Unterscheidung der Geister< bei Heinrich von Langenstein, Diss. Würzburg 1972, Würzburg 1975, konnten die übrigen vier Überlieferungsträger erschlossen werden. Vgl. die Stellenangaben in den folgenden Anmerkungen. Weitere Handschriften zur PvhG ließen sich trotz Bemühens bislang nicht ausfindig machen. Die erwähnte Habilitationsschrift ist erschienen unter dem Titel: Artes-liberales-Zyklen. Formationen des Wissens im Mittelalter (Bibliotheca Germanica 47), 2 Bde., Tübingen/Basel 2004.

${ }^{8}$ Vgl. Hohmann, Discretio spirituum [Anm. 7], Anlage (Verweis); Die deutschen Handschriften der Bayerischen Staatsbibliothek München. Cgm 691-867 [Anm. 7], S. 515-522; zur Handschrift mit weiterer Literatur auch: http://www.handschriftencensus.de/6296 (Zugriff am 23.2.2012).

${ }^{9}$ Vgl. Kurzes Verzeichnis der germanischen Handschriften der Preußischen Staatsbibliothek, von HeRmann Degering, Bd. 2: Die Handschriften in Quartformat (Mitteilungen aus der Preußischen Staatsbibliothek 8), Leipzig 1926, S. 196f.; ANNELIES Julia HofMAnN, Der EucharistieTraktat Marquards von Lindau (Hermaea NF 7), Tübingen 1960, S. 45-47; HoHMANN, Discretio spirituum [Anm. 7], S. 30 (Verweis); SIGRID KRÄMER, Handschriftenerbe des deutschen Mittelalters, Teil 1: Aachen-Kochel (Mittelalterliche Bibliothekskataloge Deutschlands und der Schweiz. Ergänzungsbd. 1), München 1989, S. 44 (zur Provenienz); MARKuS BAUMANN, Das $>$ Meisterbuch< des Rulman Merswin. Textgeschichte und Teiledition, Diss. Eichstätt 1992, S. 91f.; SABINE JANSEN, Die Texte des Kirchberg-Corpus'. Überlieferung und Textgeschichte vom 15. bis zum 19. Jahrhundert, Diss. Köln 2002, Köln 2005, S. 56; zur Handschrift mit weiterer Literatur auch: http://www.handschriftencensus.de/11948 (Zugriff am 23.2.2012).

${ }^{10}$ Vgl. Die Handschriften der Universitätsbibliothek Graz, bearb. von ANTON KeRN, Bd. 2 (Handschriftenverzeichnisse Österreichischer Bibliotheken. Steiermark), Wien 1956, S. 199f.; HOH-
} 
$\mathrm{M}=$ München, BSB, Cgm 784, fol. $146^{\mathrm{r}}-153^{\mathrm{r}}, 154^{\mathrm{r} / \mathrm{v}}$ (Vertauschung von fol. 154/153)

I + 290 Bl. (212-215 x $152 \mathrm{~mm})$ - datiert auf 1458 (fol. 157 $)$ - Provenienz: Kloster Scheyern - Schrift (Bl. 9 ${ }^{\mathrm{r}}-277^{\vee}$ ): Bastarda, einspaltig (Schreiber: Stephan Hůczgừet, Laienbruder in Scheyern, vgl. fol. $\left.157^{\vee}\right)$ - Mundart: mittelbairisch - Sammlung geistlicher Traktate und Kurztexte (Exzerpte) u. a. von Meister Eckhart, Marquard von Lindau, Heinrich von Friemar (>De IV instinctibus $<$, dt. Bearb.), Seuse. ${ }^{11}$

$\mathrm{N}=$ München, BSB, Cgm 248, fol. $195^{\text {ra }}-198^{\text {rb }}$

II + 196 Bl. (308 x 220 mm) - 2. Hälfte des 15. Jhs. - Provenienz: Kloster Tegernsee - Schrift der PvhG (Nachtrag von 2. Hand): Bastarda, zweispaltig Mundart: bairisch-österreichisch - enthält sonst, von einer Haupthand, ausschließlich deutsche Predigten des sog. Nikolaus-von-Dinkelsbühl-Redaktors. $^{12}$

\section{$\mathrm{S}=$ Salzburg, St. Peter, Cod. b V 40, fol. $342^{\mathrm{v}}-359^{\mathrm{r}}$}

467 Bl. (216 x $147 \mathrm{~mm})$ - datiert auf 1471 (Bl. 467') - Herkunft: Salzburg, Frauenkonvent St. Peter - Schrift: Bastarda, einspaltig (Schreiberin: Anna Ammanin, vgl. Bl. 467') - Mundart: bairisch-österreichisch - enthält Predigten und geistliche Texte u. a. von Tauler, Meister Eckhart, Seuse, Johannes von Indersdorf. ${ }^{13}$

MANN, Discretio spirituum [Anm. 7], Anlage (Verweis); Der Traktat Heinrichs von Friemar über die Unterscheidung der Geister. Lateinisch-mittelhochdeutsche Textausgabe mit Untersuchungen (Cassiciacum 32), hg. von ROBERT G. WARNOCK u. ADOLAR ZUMKELLER, Würzburg 1977, S. 42 (Nr. 13a) und 94-96; zur Handschrift mit weiterer Literatur auch: http://www.handschriftencensus.de/4834 (Zugriff am 23.2.2012).

${ }^{11}$ Vgl. HohmanN, Discretio spirituum [Anm. 7], S. 25-34, und Anlage; Georg STEER, Hugo Ripelin von Straßburg. Zur Rezeptions- und Wirkungsgeschichte des >Compendium theologicae veritatis $<$ im deutschen Spätmittelalter (TTG 2), Tübingen 1981, S. 351f.; Die deutschen Handschriften der Bayerischen Staatsbibliothek München. Cgm 691-867 [Anm. 7], S. 333-341; WERNER WILLIAMS-KRAPP, Die süddeutschen Übersetzungen der >Imitatio Christi<. Zur Rezeption der >Devotio moderna im oberlant, in: Aus dem Winkel in die Welt. Die Bücher des Thomas von Kempen und ihre Schicksale, hg. von UlRIKE BodEMANN u. NiKOlaUS STAUbaCH (Tradition Reform - Innovation 11), Frankfurt a. M. 2006, S. 65-79, hier S. 76 (Nr. 14); BETTiNA WAGNER, piechlein mit vil stycklein. Die Eckhart-Handschriften in der Bayerischen Staatsbibliothek München, in: Meister Eckhart in Augsburg. Deutsche Mystik des Mittelalters in Kloster, Stadt und Schule. Katalog zur Handschriftenausstellung in der Schatzkammer der Universitätsbibliothek Augsburg (18. Mai bis 29. Juli 2011), hg. von FreIMUT LÖSER, ROBERT STEINKE u. GÜNTER HÄGELE, Augsburg 2011, S. 34-48, hier S. 44 (Nr. 33); zur Handschrift mit weiterer Literatur auch: http://www.handschriftencensus.de/6282 (Zugriff am 23.2.2012).

${ }^{12}$ Vgl. HeRmann MENHARDT, Nikolaus von Dinkelsbühls deutsche Predigt vom Eigentum im Kloster, ZfdPh 73 (1954), S. 1-39, 268-291, hier S. 32; HoHMANN, Discretio spirituum [Anm. 7], S. 30 (Verweis); Die deutschen Handschriften der Bayerischen Staatsbibliothek München. Cgm 201-350, neu beschr. von KARIN SCHNEIDER (Catalogus codicum manu scriptorum Bibliothecae Monacensis. Tomus V, Editio altera, Pars 2), Wiesbaden 1970, S. 132-134; Die deutschen Handschriften der Bayerischen Staatsbibliothek München. Cgm 691-867 [Anm. 7], S. 338, 521 (Verweise); CHRISTIAN BAUER, Geistliche Prosa im Kloster Tegernsee. Untersuchungen zu Gebrauch und Überlieferung deutschsprachiger Literatur im 15. Jahrhundert (MTU 107), Tübingen 1996, S. 80, 183. Zum sog. Nikolaus-von-Dinkelsbühl-Redaktor unten, S. 62 mit Anm. 23; zur Handschrift auch: http://www.handschriftencensus.de/9444 (Zugriff am 23.2.2012).

${ }^{13}$ Vgl. Die deutschen Handschriften des Mittelalters der Erzabtei St. Peter zu Salzburg, bearb. von GEROLD HAYER (Österreichische Akademie der Wissenschaften, phil.-hist. Kl., Denkschriften, 
Die Handschriften stammen allesamt aus der Mitte bzw. zweiten Hälfte des 15. Jahrhunderts. Bei den ursprünglichen Herkunftsorten handelt es sich - soweit sich diese identifizieren lassen - vorwiegend um Benediktinerklöster, die der Melker Reform unterstehen: St. Ulrich und Afra in Augsburg, Scheyern, Tegernsee, Frauenkonvent St. Peter in Salzburg. Die Schreibermundart ist in Cgm 830 ostschwäbisch, sonst bairisch. Überlieferungskontexte der in einigen Fällen inhaltlich eng verwandten Handschriften ${ }^{14}$ verweisen auf oberdeutsche Mystik und Erbauungsliteratur. Es finden sich Namen wie David von Augsburg, Tauler, Seuse, Marquard von Lindau und Nikolaus von Dinkelsbühl, ferner Texte der Altväterliteratur. Die nachstehenden Ausführungen folgen der Handschrift aus St. Ulrich und Afra in Augsburg (Cgm 830), dem ältesten Textzeugen, der die >Predigt vom heiligen Geist< am sorgfältigsten und zuverlässigsten überliefert. ${ }^{15}$

Im Hinblick auf Einteilungsschemata der mittelalterlichen Ars praedicandi ${ }^{16}$ läßt sich die inhaltliche Gliederung der Predigt wie folgt beschreiben:

Den einleitenden Textspruch (Z. 2) liefert ein Satz aus dem Johannes-Evangelium: Wann nun kompt der gaüst der warhaÿt, so wirtt er eüch lernen alle warhaÿt (Io 16,13). Dieser Satz gehört zu einer Schriftlesung - Io 16,5-14 -, die im liturgischen Jahr ihren festen Platz hat. In den Perikopen des römischen und monastischen Ritus ${ }^{17}$ erscheint sie am vierten Sonntag nach Ostern, also zur

Bd. 154; Veröffentlichungen der Kommission für Schrift- und Buchwesen des Mittelalters, Reihe III, Bd. 1), Wien 1982, S. 286-296; Die deutschen Handschriften der Bayerischen Staatsbibliothek München. Cgm 691-867 [Anm. 7], S. 338 (Verweis); JoHANNES GotTFRIED MAYER, Die >Vulgata<-Fassung der Predigten Johannes Taulers. Von der handschriftlichen Überlieferung des 14. Jahrhunderts bis zu den ersten Drucken (Texte und Wissen 1), Würzburg 1999, S. 266f.; Pseudo-Engelhart von Ebrach. Das Buch der Vollkommenheit (Deutsche Texte des Mittelalters 86), hg. von KARIN SCHNEIDER, Berlin 2006, S. XIX; zur Handschrift mit weiterer Literatur auch: http://www.handschriftencensus.de/8426 (Zugriff am 23.2.2012).

${ }^{14}$ Vgl. bes. den engen Zusammenhang von A, G, M. Dazu Werner Höver, Theologia Mystica in altbairischer Übertragung. Bernhard von Clairvaux, Bonaventura, Hugo von Balma, Jean Gerson, Bernhard von Waging und andere (MTU 36), München 1971, S. 189f., 236; synoptische Übersicht bei HoHmanN, Discretio spirituum [Anm. 7], Anlage; DERS., Heinrichs von Langenstein $>$ Unterscheidung der Geister<, lateinisch und deutsch. Texte und Untersuchungen zu Übersetzungsliteratur aus der Wiener Schule (MTU 63), Zürich/München 1977, S. 9.

${ }^{15}$ Dieses Urteil gründet sich auf die gewissenhafte Einrichtung der Handschrift (Rubrizierung, Randnotizen), ferner auf die Tatsache, daß Cgm 830 den Text vergleichsweise am vollständigsten wiedergibt. In den übrigen Handschriften finden sich wiederholt Auslassungen, etwa derart, daß bei zwei aufeinanderfolgenden Autoritätenzitaten (Es spricht X: [Zitat x]. Es spricht Y: [Zitat y]) das Zitat $\mathrm{x}$ und die darauffolgende inquit-Formel von $\mathrm{Y}$ entfallen, wodurch das Zitat y fälschlich unter der inquit-Formel von X läuft, ein Versehen, das sich durch Quellennachweis als Fehler bestimmen läßt. - Die Textwiedergabe entspricht dem nachfolgenden Textabdruck.

${ }^{16} \mathrm{Vgl}$. TH[OMAS]-M[ARIE] CHARLAND, Artes Praedicandi. Contribution à l'histoire de la rhétorique au Moyen Age (Publications de l'Institut d'Études Médiévales d'Ottawa 7), Paris/Ottawa 1936; JAMES J. MuRPHY, Rhetoric in the Middle Ages. A History of Rhetorical Theory from Saint Augustine to the Renaissance, Berkeley [usw.] 1974, S. 269-355; AlbERT LANG, Die Katharinenpredigt Heinrichs von Langenstein. Eine programmatische Rede des Gründers der Wiener Universität über den Aufbau der Glaubensbegründung und die Organistation der Wissenschaften. II. Charakter und Aufbau der Katharinenpredigt, Divus Thomas (Freiburg/Schweiz) 26 (1948), S. 233-250, bes. S. 239-245.

${ }^{17}$ Vgl. z. B. zum römischen Ritus: Liber missalis secundum breviarium chori ecclesie Ratisponen- 
Vorbereitungszeit des Pfingstfestes. In der >Predigt vom heiligen Geist $<$ wird der Satz mit Berufung auf Autoritäten wie Dionysius Areopagita und Augustinus dahingehend gedeutet, daß der Wille des Menschen dem Willen Gottes entsprechen solle (Z. 4-18). Dies in dreierlei Hinsicht: gemäß dem physischen Vermögen (vermüglichaÿt) des Menschen sowie gemäß seinen intellektuellen und emotionalen Fähigkeiten (erkanttlichait - begirlichait). Solchermaßen den Willen Gottes zu erfüllen, lehre der heilige Geist, von dem Johannes im 16. Kapitel sage: >er wird euch lehren alle Wahrheit< (Z. 19-36).

Mit dem Stichwort >lehren< ist nun das Thema der Predigt benannt: Laut dem heiligen Augustinus sei ware gaÿstlichä̈t ... ain schull aller tugend und zucht (Z. 37f.). In dieser Schule wirke der heilige Geist als Erzieher und lehre die süben frë̈en künst gaÿstlich zu verstan (Z. 50f.). Es schließt sich eine Deutung der einzelnen Artes an. Sie erfolgt im Rahmen einer gliedernden Übersicht des Themas (divisio, Z. 51-58):

Dann zü dem ersten so lert er uns durch die Gramatick leben in rainikaÿt der gewissen.

Züm andern durch Loÿcam lert er uns die welt verschmächen und fliechen.

Züm dritten lert er uns durch Rethorick under gott in gemüt und dem gaüst gediemütiget werden.

Züm vierden durch Musick lert er uns diemütiklich betten.

Züm fünften durch Arismetricam lert er uns zelen die güttät gotz und darumb danckpar sein.

Züm sechsten durch Geometrÿ lert er uns messen ÿrdische ding und hÿmlische.

Züm sÿbenden durch Astronomÿ lert er uns nachvolgen dem leben der haÿligen vätter.

Diese Interpretation der freien Künste wirkt einigermaßen willkürlich, doch ist sie im einzelnen sorgfältiger gestrickt, als dies im Überblick der divisio zunächst den Anschein hat. Die anschließende Durchführung (prosecutio) macht dies deutlich. Dort heißt es beispielsweise von der Grammatik (Z. 60-63):

Zu dem ersten lert uns der hä̈lig gaist Gramatick, die da ist ain grundfest aller kunst, dann sü lert lesen verstan und ordenlich reden. Also auch der hä̈lig gä̈st lert uns züm ersten rainikaÿt der gewissen, die da ist ain anfang und zierd aller tugend.

Die Grammatik wird gemäß der spätantik-mittelalterlichen Lehrtradition als grundfest aller kunst ${ }^{18}$ verstanden. Damit ist das tertium comparationis für die

sis, Johannes Sensenschmidt \& Johannes Bekenhaub, Regensburg 1485, S. CXX $/ \mathrm{CXXI}^{\mathrm{r}}$; Missale secundum ritum Augustensis ecclesie, Erhard Ratdolt, Augsburg 1510, S. LXXX' ; ferner PAUL PIETSCH, Ewangely und Epistel Teutsch. Die gedruckten hochdeutschen Perikopenbücher (Plenarien) 1473 - 1523. Ein Beitrag zur Kenntnis der Wiegendrucke, zur Geschichte des deutschen Schrifttums und der deutschen Sprache, insbesondere der Bibelverdeutschung und der Bibelsprache, Göttingen 1927, S. 68. Zum monastischen Ritus bei den Benediktinern: Missale sacerrimi ordinis beati Benedicti, Johannes Sensenschmidt, Bamberg 1481, S. XCIII'; in den Bettelorden: MaURA O' CARRoll, The Lectionary for the Proper of the Year in the Dominican and Franciscan Rites of the Thirteenth Century, Archivum Fratrum Praedicatorum 49 (1979), S. 79103, hier S. 94.

${ }^{18}$ Fundamentum liberalium litterarum - so schon Cassiodor (Cassiodori Senatoris Institutiones, hg. von R[OGER] A[UBREY] B[ASKERVILLE] MYNORS, Oxford 1937, ${ }^{2}$ 1963, Lib. II,4, S. 91, Z. 5) und 
Auslegung gewonnen: Wie die Grammatik die Basis aller übrigen Studienfächer liefert, so gilt ein reines Gewissen als anfang und zierd aller tugend.

Die Deutung der Rhetorik lautet folgendermaßen (Z. 154-159):

Zü dem dritten so lert der hä̈lig gaist Rethorick. Die selbig kunst lert klugglich reden latein und brieff schreiben, dar inn sich ainer gegen dem andern nidert und diemütiget. Also der haÿlig gaist, wann er uns macht gott rainiklichen dienen und den leib, welt und den bösen gaist verschmechen, so macht er dann, das wir uns in ainem verlaugen aigens willes gott diemütiklich underwerffen [...].

Der Absatz beruft sich auf die mittelalterliche Brieflehre (Ars dictaminis): Rhetorik lehre nicht nur, auf Lateinisch verständig zu reden, sondern unterrichte außerdem in der Kunst des Briefeschreibens, dar inn sich ainer gegen dem andern nidert und diemütiget. Hier bildet die Stilistik von Demutsformeln, wie sie die Brieflehre enthält, das tertium comparationis für die Auslegung der Rhetorik auf demütige Gottesfurcht.

Durch Arithmetik, die Rechenkunst, leite der heilige Geist dazu an, die göttlichen Heilstaten zu zählen, und folglich dafür dankbar zu sein (Z. 192-195):

Züm fünfften so lert uns der hä̈lig gaist Arismetrick. Dann er lert uns zelen alle güttät gotz uns geschechen, alz die schöpffung und widerschöpffung, erlösung, gebung der sacrament und verhayssung seins reichs.

Wann wir nun das wöl gezellen, so gehört darzü ain sagen der danckpärkä̈t.

Und Astronomie schließlich beobachte den Lauf der Planeten, entsprechend mahne der heilige Geist, dem Vorbild der Altväter - gleich Leitpunkten am Himmel - zu folgen (Z. 223-225):

Zü dem sybenden lert uns der hä̈lig gaist Astronomÿ. Das ist schawen den lauff der planeten und sterrn. Das ist, er lert uns mercken das leben der haÿligen vätter.

Die Artes-Deutungen werden jeweils ausführlich durch Zitate der Bibel und Kirchenlehrer abgestützt. Zur Illustration sind vereinzelt auch Exempla eingestreut. Die Anlage zweier Abschnitte soll in einem nächsten Analyseschritt exemplarisch untersucht werden, doch ist zuvor der Aufbau der Predigt und ihre argumentative Stoßrichtung weiter zu verfolgen.

Der Artes-Auslegung schließt sich ein Abschnitt an, in dem drei Bücher vorgestellt werden, durch die der heilige Geist seine Lehre vermittelt (Z. 245-329). Die Bücher richten sich an je verschiedene Zielgruppen, die in ihrer religiösen Entwicklung unterschiedlich weit fortgeschritten sind. Den Hintergrund des Abschnitts liefert die im geistlichen Schrifttum des Mittelalters verbreitete Auffas-

Isidor von Sevilla (Isidori Hispalensis Episcopi Etymologiarum sive Originum Libri XX, hg. von W[ALLACE] M[ARTIN] LinDSAY, Oxford 1911, ${ }^{6} 1985$, Lib. I,V,1). Vgl. zur grundlegenden Funktion der Grammatik innerhalb des Artes-Studiums auch R[UDOLF] WITTKOWER, Grammatica: From Martianus Capella to Hogarth, Journal of the Warburg Institute 2 (1938/39), S. 82-84, hier S. 83; JeFFrey F. HunTSMAN, Grammar, in: The Seven Liberal Arts in the Middle Ages, hg. von DAVID L. WAGNER, Bloomington (Indiana) 1983, S. 58-95, hier S. 59-61; STOLZ, Artes-liberales-Zyklen [Anm. 7], S. 58f. 
sung von der Welt als Buch. So wird den anfachenden menschen das Buch vom Erdreich zum Studium vorgelegt, den würckenden jenes des Firmaments, den volkommen menschen jenes des Feuerhimmels (Z. 246-248). ${ }^{19}$ Mit diesem Aufstieg vom Erdboden zu den Höhen des Coelum empyreum findet die Predigt im übrigen einen eleganten Anschluß zur Disziplin der Astronomie, die unmittelbar zuvor beschrieben wird.

Die allegorische Deutung der drei Bücher bzw. der durch sie repräsentierten Räume gestaltet sich folgendermaßen:

Die Erde als schwächstes der Elemente verweist die Anfangenden auf ihre moralische Unzulänglichkeit (Z. 249-269). In diesem Zusammenhang erfolgen Anweisungen zum rechten Verhalten in der Klostergemeinschaft.

Das Firmament, der täglich die Welt umkreisende Sternenhimmel, mahnt sodann die in ihrem religiösen Streben bereits weiter Fortgeschrittenen, Tag für Tag ihren christlichen Pflichten nachzukommen und so ihren lauff zu vollbringen (Z. 270-318). ${ }^{20}$

Der Feuerhimmel schließlich veranlaßt die Vollkommenen, sich in göttlicher caritas zu entzünden und ihren Nächsten als Vorbild zu leuchten (Z. 319-329).

An dieser Stelle bricht die Predigt mit einer kurzen Gebetsformel (verleich uns der allmächtig gott. Amen) ab. Ein ausführliches Schlußwort fehlt, doch ist dieses Fehlen in Theorie und Praxis der mittelalterlichen Predigt durchaus verbreitet. $^{21}$

Insgesamt gesehen bekundet die >Predigt vom heiligen Geist< einen stark moralisierenden Impetus. Bestände mittelalterlichen Wissens - die Artes, Erdund Himmelskunde - werden hier dazu genutzt, ein offensichtlich klösterliches Publikum zu religiösem Verhalten anzuleiten. Deutlich lassen sich Bezüge zum Programm der >Vierundzwanzig goldenen Harfen « des Johannes Nider erkennen. Hier wie dort wird der Aufstieg zu christlicher Vollkommenheit beschrieben, hier wie dort fungiert die Askese der frühchristlichen Wüstenväter als leitendes Vorbild.

${ }^{19}$ Vgl. zur Vorstellung der Welt als Buch HANs BLUMENBERG, Die Lesbarkeit der Welt, Frankfurt a. M. ${ }^{2} 1983$, S. 47-67; Hubert Herkommer, Buch der Schrift und Buch der Natur. Zur Spiritualität der Welterfahrung im Mittelalter, mit einem Ausblick auf ihren Wandel in der Neuzeit, in: Nobile claret opus. Festgabe für Frau Prof. Dr. Ellen Judith Beer zu 60. Geburtstag (= Zeitschrift für Schweizerische Archäologie und Kunstgeschichte 43, H. 1, 1986), S. 167-178 (mit weiterer Literatur). Zum verbreiteten Modell des Dreistufenwegs vom anfangenden über den fortschreitenden (würckenden) zum vollkommenen Menschen, das sich u. a. in Bonaventuras >De triplici via< (Kap. 25,3) greifen läßt, KURT RUH, Geschichte der abendländischen Mystik, Bd. 2: Frauenmystik und Franziskanische Mystik der Frühzeit, München 1993, S. 428-431.

${ }^{20}$ Eingefügt ist hier ein Exempel aus dem leben der vätter (Z. 280-318): Ein Engel führt einen gütten brider an fünf Orte, die in ihrer Eigenart bzw. mit ihren Bewohnern Verfehlungen geistlichen Lebens bezeichnen. Zuletzt zeigt der Engel dem Bruder ein Haus mit Kristallfeuer als Sinnbild geistlicher Läuterung. Es ist mir bislang, auch nach der Befragung von Spezialisten, nicht gelungen, eine Quelle zu eruieren. In den gängigen Fassungen der >Vitas patrum < scheint die Erzählung nicht nachweisbar zu sein.

${ }^{21}$ Vgl. ChaRland [Anm. 16], S. 217f.; Murphy [Anm. 16], S. 325, 331f., 333; LANG [Anm. 16], S. 244. 
Diese moralisierende Ausrichtung dürfte in Verbindung mit monastischen Reformbewegungen des 15. Jahrhunderts stehen. Für Johannes Nider ist ein solcher Bezug im Zusammenhang mit der dominikanischen Observanzbewegung und der Reform des Nürnberger Katharinenklosters erwiesen. Für die anonyme >Predigt vom heiligen Geist< ist an die Melker Reform ${ }^{22} \mathrm{zu}$ erinnern, die sich, gefördert von Angehörigen und Absolventen der Wiener Universität, in österreichischen und bayerischen Benediktinerklöstern abspielt - so u. a. in Überlieferungszentren der Predigt wie St. Ulrich und Afra in Augsburg, Scheyern, Tegernsee und St. Peter in Salzburg. Die Tegernseer Handschrift ( $\mathrm{N}=\mathrm{Cgm} 248$ ) liefert sogar einen besonders deutlichen Hinweis auf die Melker Reform. Neben der am Schluß von zweiter Hand angefügten >Predigt vom heiligen Geist< finden sich dort ausschließlich deutsche Predigten nach Nikolaus von Dinkelsbühl, dem bedeutenden Wiener Universitätslehrer und führenden Initiator der Melker Reformbewegung. ${ }^{23}$

Die in der >Predigt vom heiligen Geist $<$ wohl vor diesem Hintergrund vorgenommene Moralisierung von Artes-Wissen soll im folgenden näher untersucht werden. Dazu sind zwei besonders aussagekräftige Abschnitte heranzuziehen, jener zur Logik (Z. 104-153) und jener zur Musik (Z. 173-191).

Die moralisierende Deutung der Logik gründet sich auf die Unterscheidung von wahren und falschen Aussagen (Z. 104f.), einem klassischen Bestandteil des dialektisch-logischen Lehrprogramms. ${ }^{24}$ Außerdem heißt es, daß die Logik das straffen lehre (Z. 105). Damit ist ein Hinweis auf die Rechtspraxis gegeben,

${ }^{22}$ Vgl. VIRGIL REDLICH, Tegernsee und die deutsche Geistesgeschichte im 15. Jahrhundert (Schriftenreihe zur bayerischen Landesgeschichte 9), München 1931; GERDA KOLLER, Princeps in ecclesia. Untersuchungen zur Kirchenpolitik Herzog Albrechts V. von Österreich (Archiv für österreichische Geschichte 124), Wien 1964, S. 78-111; JOACHIM ANGERER, Die liturgisch-musikalische Erneuerung der Melker Reform. Studien zur Erforschung der Musikpraxis in den Benediktinerklöstern des 15. Jahrhunderts (SB der österreichischen Akademie der Wissenschaften, phil.-hist. Kl., Bd. 287, Abh. 5; Veröffentlichungen der Kommission für Musikforschung 15), Wien 1974, S. 29-75; META NIEDERKORN-BRUCK, Die Melker Reform im Spiegel der Visitationen (Mitteilungen des Instituts für Österreichische Geschichtsforschung. Ergänzungsbd. 30), Wien/München 1994; BAUER [Anm. 12], bes. S. 7-9; UlRIKE TREUSCH, Bernhard von Waging $(† 1472)$, ein Theologe der Melker Reformbewegung. Monastische Theologie im 15. Jahrhundert? (Beiträge zur historischen Theologie 158), Tübingen 2011.

${ }^{23}$ Vgl. oben, S. 58. Zu Nikolaus von Dinkelsbühl: ALOIS MADRE, Nikolaus von Dinkelsbühl. Leben und Schriften. Ein Beitrag zur theologischen Literaturgeschichte (Beiträge zur Geschichte der Philosophie und Theologie des Mittelalters 40,4), Münster 1965; DERS., Nikolaus von Dinkelsbühl, ${ }^{2}$ VL VI, Sp. 1048-1059; zu seiner Rolle bei der Melker Reform HoHManN, Heinrichs von Langenstein >Unterscheidung der Geister< [Anm. 14], S. 273f., DERS., Die recht gelerten maister [Anm. 5], S. 351. Die unter Nikolaus' Namen laufenden deutschen Predigten sind wohl alle das Werk eines Redaktors; dazu MENHARDT [Anm. 12], und bes. Hohmann, Die recht gelerten maister [Anm. 5], S. 360f., DERS., Nikolaus-von-Dinkelsbühl-Redaktor, ${ }^{2}$ VL VI, Sp. 1059-1062.

${ }^{24}$ Vgl. PierRe Michaud-QuAntin, L'Emploi des termes logica et dialectica au Moyen Age, in: Arts libéraux et philosophie au Moyen Age. Actes du quatrième congrès international de philosophie médiévale. Université de Montréal, Montréal, Canada, 27 août - 2 septembre 1967, Montréal/Paris 1969, S. 855-862; JAN PINBORG, Logik und Semantik im Mittelalter. Ein Überblick. Mit einem Nachw. von Helmut KoHLEnBerger (Problemata 10), Stuttgart-Bad Cannstatt 1972, S. 65-69; STOLZ, Artes-liberales-Zyklen [Anm. 7], S. 59-61. 
einen der Anwendungsbereiche logischer Techniken im Mittelalter. ${ }^{25}$ In der Auslegung werden die benannten Lehrgegenstände dahingehend interpretiert, daß der heilige Geist den Menschen ermahne, Wahres vom Falschen zu sondern und zu streitten wider das flaÿsch, wider die welt und den bösen gaist (Z. 107f.). Das straffen als Applikation logischen Bemühens wird hier also bezogen auf die Abwehr von Anfechtungen wie Fleischeslust, weltlichem Genuß und übler Gesinnung. Die anschließende Durchführung folgt streng dieser Anordnung. Nacheinander treten Personifikationen des Leibes, der Welt und des bösen gaists auf, um ihre Standpunkte vorzutragen. Stets jedoch werden die Argumente durch den heiligen Geist entkräftet, der die Einwände seinem Schüler vorgibt. Das Verfahren ähnelt jenem einer logischen Disputation, wo sich zunächst gegensätzliche Meinungen im Pro und Contra kreuzen, um anschließend einer Conclusio zugeführt zu werden ${ }^{26}$ Im Hintergrund könnten auch Textsammlungen wie Abaelards $>$ Sic et non< stehen, die einander widersprechende Bibel- und Autoritätenzitate gegenüberstellen.

So führt im ersten Teilabschnitt (Z. 109-117) der personifizierte Leib eine Stelle aus dem alttestamentlichen Buch Ecclesiastes an (nicht Ecclesiasticus, wie alle sechs Handschriften an dieser Stelle glauben machen): Ich han gelobt die fröd der menschen. Was ist bessers under dem hÿmel dann essen und trincken, wol leben und wollust haben (Z. 110f., nach Ecl 8,15). Unverzüglich erfolgt die Replik mit einem Wort aus Paulus' Galaterbrief: Aber der haÿlig gä̈st lertt sein schuler anttwurtten, das da spricht der zwölffpott: Die in lust des leibs send, mügent Cristo nit wol gefallen. Der leib begert wider den gaist und der gaist wider den leib (Z. 111-114, nach Gal 5,16f.). Eine zweite Replik beruft sich auf den Philosophen Aristoteles: Es spricht auch Aristotiles: Wollust ist wider wollust, alz ob er spräch: wollust des leibs ist wider wollust des gaists (Z. 114f.). ${ }^{27}$ Zusammen mit dem Galaterbrief wird hier also ein dem antiken Philosophen zugeschriebener Satz gegen das alttestamentliche Ecclesiastes-Zitat ausgespielt. Die im Rekurs auf Aristoteles gewonnene Unterscheidung zweier Arten von Wollust, jener des Leibes und jener des Geistes, dient auch als Grundlage der abschließenden Conclusio. Diese spricht sich zu Lasten leiblicher Annehmlichkeiten für ein Leben im Geiste aus: Wann nun der gaist ist ainer hÿmlischen natur und der leib ainer $\ddot{y}$ rdischen, darumb so sol man dem gaist leben (Z. 115117).

${ }^{25}$ Vgl. AnNetTe Volfing, Heinrich von Mügeln. >Der meide kranz $\prec$. A Commentary (MTU 111), Tübingen 1997, S. 76.

${ }^{26}$ Vgl. L[UDwIG] HödL u. a., Disputatio(n), LexMa III, Sp. 1116-1120; JÜRGEN MIETHKE, Die mittelalterlichen Universitäten und das gesprochene Wort (Schriften des historischen Kollegs. Vorträge 23), München 1990; Olga WeIJERS, Queritur utrum. Recherches sur la disputatio dans les universités médiévales (Studia artistarum 20), Turnhout 2009; ANITA TranINGER, Disputatio. Medien und Gattungen europäischer Wissensverhandlungen zwischen Scholastik und Humanismus (Text und Kontext), Stuttgart 2012.

${ }^{27}$ Zur Unterscheidung von delectatio corporalis und delectatio spiritualis vgl. beispielsweise Thomas von Aquin: In quattuor libros sententiarum, hg. von R. BUSA [u. a.] (S. Thomae Aquinatis Opera omnia 1), Stuttgart-Bad Cannstatt 1980, IV, ds 49, qu 3, ar 4a, rc 2, S. 693. 
Die beiden nächsten Teilabschnitte lassen dasselbe argumentative Grundmuster erkennen, obschon dort die Schlußfolgerung jeweils spezifische Ausformungen annimmt.

$\mathrm{Zu}$ Beginn des zweiten Absatzes legitimiert sich die personifizierte Welt durch ein Psalmenzitat Gott hatt dem herren geben den himel, aber das ertrich hatt er geben den sünen der menschen (Z. 119f., nach Ps 113,24). Der heilige Geist kontert mit einem Vers aus dem ersten Johannesbrief: Ir send nit lieb haben die welt noch die ding, die in der welt sind (Z. 122, nach I Io 2,15). Ein zweiter Einwand argumentiert mit Sprüchen des Weisen aus jenem Buch Ecclesiastes, das eingangs der personifizierte Leib gegen den heiligen Geist ins Feld geführt hat: Ich han gesechen alle ding, die under der sunnen send und gehandelt werdent, und die send nichtzit anderst dann ain üppikä̈t der üppikaÿt und ain peinigung des gaistz (Z. 123-126, nach Ecl 1,14).

Anstelle einer eigentlichen Conclusio folgt nunmehr ein illustratives Exempel, das zusätzlich durch Autoritätenzitate abgestützt wird (Z. 127-144). Es handelt sich um den Topos der Frau Welt, der in spätmittelalterlichen Text- und Bildzeugnissen mannigfach ausgeprägt ist. $\mathrm{Zu}$ erinnern wäre an Exempelsammlungen, Predigten und Verserzählungen wie z. B. Konrads von Würzburg >Der Welt Lohn<, ferner an ikonographische Darstellungen, etwa die Skulptur am Südportal des Doms zu Worms. ${ }^{28}$ Wie Konrad von Würzburg so schildert auch die >Predigt vom heiligen Geist< die Begegnung eines Ritters mit einer bezaubernden Dame. Doch enthüllt ein Blick auf den Rücken der Frau Welt deren wahres Wesen. In der >Predigt vom heiligen Geist< gestaltet sich die Entdeckung des Ritters wie folgt: Da sach er ain ofen prinnen mit schwebel und bech und über all maß übel schmecken. Da sprach der ritter: $O$ wie ain gro $\beta$ wunder ist das, daz du fornan die aller schönest bist under den weiben und hinden ain prinnender ofen. Was bist du? Die fraw anttwurt: Ich bin die welt, die iren liebhabern gar lieblich und ir spiegel ist, aber das end ist der tod (Z. 131-135).

Die im Für und Wider der Argumente bereits dialogisch angelegte Disputation wird auf diese Weise durch ein zusätzliches Zwiegespräch - jenes zwischen Ritter und Welt - bereichert. Im Rahmen des eingestreuten Exempels dient es dazu, die moralisierende Lehre der Logik zu veranschaulichen und deren Deutung auf Weltverachtung zu verlebendigen.

Mit Sentenzen zum trügerischen Schein des mundus immundus bekräftigen Bernhard von Clairvaux und Gregor der Große die Aussage: Alz das dann wol betrachtet Sant Bernhart da er sprach: $O$ du unraine welt, warumb haltest du die menschen also, und du doch zergenklich und in tod fürend bist, was tätest,

${ }^{28} \mathrm{Vgl}$. die Angaben bei Frederic C. TUBACH, Index exemplorum. A Handbook of Medieval Religious Tales (FFC 204), Helsinki 1969, Nr. 5390, S. 407f.; Erläuterungen bei WoLFGANG StAMMLER, Frau Welt. Eine mittelalterliche Allegorie (Freiburger Universitätsreden NF 23), Freiburg/Schweiz 1959, S. 46f., 104f. (Anm. 141f.), u. HubERT HerkomMER, Frau Welt und Fortuna, Kreis und Quadrat. Weltbilder des europäischen Mittelalters, in: Weltbilder, hg. von MaJa Svilar u. Stefan KunZE (Kulturhistorische Vorlesungen 1991/92), Bern [usw.] 1993, S. 177-228, hier S. 177-188. 
soltest du ewenklich stan? Es spricht Gregorius: Die welt gronet in vil menschen herczen, wie wol sÿ doch in ir selbs dorret (Z. 135-139). ${ }^{29}$ Damit entfällt eine reguläre Conclusio, doch dürfte sie sich angesichts der Drastik des Exempels erübrigen.

Im dritten Teilabschnitt tritt - nach der Leibes- und Weltlust - nunmehr üble Gesinnung in der Personifikation eines bösen gaists auf (Z. 145-147). Dieser plädiert dafür, äußere Vorzüge wie Vornehmheit, Jugend, Reichtum und Schönheit ungehemmt zu genießen, da im Alter noch genug Zeit zur Reue bleibe. ${ }^{30}$ Die Erwiderung, die der heilige Geist seinem Schüler empfiehlt, fällt recht heftig aus. Sie ergießt sich in einer Fülle von biblischen Zitaten und ächtet dabei vor allem den Genuß von Jugend und Wohlstand. Aufgeboten werden das Vade retro me Satana (Mc 8,33), ferner Paulus' Warnung vor einem jähen Tod (I Th 5,3), schließlich Schmähungen des Reichtums aus dem Alten Testament (Iob 27,19; Ps 48,17 f. u. 48,11$)$.

Auch hier fehlt eine eigentliche Conclusio. An ihre Stelle tritt - Z. 151-153 eine den gesamten Abschnitt zur Logik beschließende Mahnung, für Gottes Gaben, seien sie materiell oder geistig, dankbar zu sein. Diese Wendung erfolgt recht unvermittelt, doch fungiert sie offensichtlich als Vorausverweis auf einen der nachfolgenden Abschnitte, jenen Passus, der die Arithmetik auf Dankbarkeit für Gottes Heilstaten deutet.

Dieser Gestus steht nicht singulär, sondern liegt der Predigt als generelle Formtendenz zugrunde. Wiederholt werden einzelne Abschnitte durch solche Querverweise miteinander verfugt. So betont etwa der Absatz zur Logik eingangs, daß der heilige Geist den Menschen zu lautterkä̈t der gewissen anleite (Z. 106). Auf Reinheit des Gewissens aber zielt die Auslegung der Grammatik im unmittelbar vorausgehenden Abschnitt. Ähnlich bezieht sich die Interpretation der Rhetorik auf die beiden im Trivium vorangehenden Künste Grammatik und Logik (vgl. oben, S. 60). Zu Beginn fallen dort nochmals die deutenden Stichwörter zur Grammatik - gott rainiklichen dienen (Z. 156f.) - sowie zur Logik - leib, welt und den bösen gaist verschmechen (Z. 157) -, ehe die Auslegung der Rhetorik auf die Demut erfolgt. Die Komposition der Predigt weist damit eine sorgfältige Planung auf.

Das zweite hier näher zu betrachtende Textbeispiel betrifft die Fächergruppe des Quadriviums. Es handelt sich um die Moralisierung der Musik, welche für die auf die Logik folgenden Artes-Deutungen ein recht typisches Beispiel abgibt. In ihrer Anlage sind diese Absätze weniger aufwendig gebaut, auch ist ihre Darstellungsweise weniger lebendig gehalten. Selbst hinsichtlich des Umfangs

${ }^{29} \mathrm{Vgl} \mathrm{zu} O$ du unraine welt ... ewenklich stan?: Opera Quodvultdeo Carthaginensi episcopo tributa, hg. von R[ENÉ] BRAUn (CC 60), Turnhout 1976, Sermo de symbolo III, I,20, S. 350: O munde immunde, teneris periens; quid faceres si maneres?; zu Die welt ... dorret: Gregor der Große, Homiliae in Evangelia, Homilia XXVIII,3, PL 76, Sp. 1212 D: et tamen cum in seipso floreret, jam in eorum cordibus mundus aruerat.

${ }^{30}$ Mit diesem Argument setzen sich auch Predigten auseinander, die unter dem Namen des heiligen Augustinus überliefert sind; vgl. z. B. Sermo CCXCIII,4, PL 39, Sp. 2302. 
läßt sich eine Verminderung beobachten: gegenüber der Grammatik und Logik sind die Passagen um etwa die Hälfte reduziert. Diese Schmälerung könnte damit zusammenhängen, daß der anonyme Verfasser die nachlassende Aufnahmefähigkeit des Publikums beim Vortrag mit einberechnet hat. Damit liegt vermutlich das Indiz für eine orale Vermittlung der Predigt vor. Es scheint sich abzuzeichnen, daß die Predigt tatsächlich auf mündliche Rezitation hin angelegt war, auch wenn sie in der Manuskript-Überlieferung ausschließlich als schriftliche Aufzeichnung vorliegt und mit typischen Merkmalen der Schriftlichkeit wie Rubrizierung oder Randnotizen versehen ist. Greifbar wird das Substrat eines oralen Gebrauchszusammenhangs.

Mündliche Artikulationsweisen werden im übrigen auch innerhalb der einzelnen Abschnitte thematisiert. Den deutlichsten Beleg liefert der Passus zur Logik, wo ein Rekurs auf die mündliche Praxis der Disputation erfolgt. Doch verweist auch der Absatz zur Musik (Z. 173-191) auf mündliche Darbietungsformen, dies im Zusammenhang mit der Mehrstimmigkeit des liturgischen Gesangs.

Der Abschnitt beginnt mit einer spirituellen Interpretation der Disziplin: $Z_{u}^{o} m$ vierden so lert der haylig gaist Musick. Das ist wol singen in gaÿstlicher fröd (Z. 173f.). Ein Augustinus zugeschriebener Leitspruch bekräftigt die Deutung: Wie die natürliche Stimme nicht ohne den leiplichen gaist, den Geist im menschlichen Körper, sein könne, so könne die geistliche Stimme nicht ohne den heiligen Geist sein (Z. 174f.). ${ }^{31}$ Ergänzend ist ein Psalmenvers angeführt, der hier als Prophetenspruch läuft: Singent dem herren ain nü gesang, dan er hatt wunderbere ding getan (Ps 97,1; Z. 176f.).

Was mit der >geistlichen Stimme< gemeint ist, wird anschließend durch eine Allegorie erläutert (Z. 177-184). Sie nimmt Bezug auf die Dreistimmigkeit in der zeitgenössischen Choralkunst; im Hintergrund der Ausführungen dürfte die Anlage polyphoner Kompositionen wie der Motette ${ }^{32}$ stehen. Die >Predigt vom heiligen Geist< stellt fest, das in ainem ÿeglichen maisterlichen gesang drë̈ stimm send, die under, die mittel und die höchst (Z. 177f.). Die Ausdeutung dieser drei Stimmlagen lautet: Also sol auch in dem gaistlichen gesang sein drë̈ stimm, das ist die stimm des herczen, des munds und des wercks (Z. 178-180). Auf den Mund wird die unterste Stimme bezogen, der sogenannte tenor in der polyphonen Liedkunst des Mittelalters (Z. 180). Die Mittelstimme, der medius

\footnotetext{
${ }^{31}$ Nach Augustinus, Enarrationes in Psalmos, Bd. 1, hg. von D. Eligius DeKKERS u. JohANNES FraIPONT (Aurelii Augustini Opera 10,1; CC 38), Turnhout 1956, Ps 5, § 2, Z. 5f., S. 19f.: quandoquidem uox corporalis auditur, spiritalis autem intellegitur.

${ }^{32}$ Vgl. Ludwig FinsCHER, Motette, MGG IX, Sp. 637-669. Zur Entwicklung im 15. Jahrhundert: LUDWIG FINSCHER/ANNEGRIT LAUBENTHAL, Cantiones quae vulgo motectae vocantur. Arten der Motette im 15. und 16. Jahrhundert, in: Die Musik des 15. und 16. Jahrhunderts. Teil 2, hg. von LUDWIG FINSCHER (Neues Handbuch der Musikwissenschaft 3,2), Laaber 1990, S. 277-370; LAURENZ LÜTTEKEN, Motette. B.IV: 15. und 16. Jahrhundert, ${ }^{2}$ MGG Sachteil VI, Sp. 513-528. $\mathrm{Da} ß$ die Melker Reform eine Verdrängung der in den Benediktinerklöstern gepflegten Mehrstimmigkeit vorsah, zeigt ANGERER [Anm. 22], S. 95-115, 123f.; doch stellt sich die Frage, inwieweit diese Normvorschriften in der Praxis tatsächlich durchgesetzt wurden, vgl. ebd., S. 164f.
} 
cantus oder motetus im engeren Sinne, bezeichnet die Werke; die Oberstimme schließlich, der tertius cantus oder das triplum, steht für eine andächtige Gesinnung des Herzens (Z. 182f.). ${ }^{33}$ Im Rückverweis auf die mittelalterliche Choralkunst wird hier also das harmonische Zusammenwirken dreier devotionaler Praktiken empfohlen: das mündliche Gotteslob im Gebet, das Tätigsein in guten Werken und andächtige Herzensgesinnung sollen sich gegenseitig ergänzen. Dabei ist eine klare hierarchische Stufung erkennbar, die beim Gebet ansetzt, über die Tätigkeit guter Werke führt und in andächtiger Haltung gipfelt. Bloßes Lippenbekenntnis reicht nicht aus, wie der Verfasser im Anschluß an Isaias betont (Z. 181f., nach Is 29,13). Denn, so das Fazit: wär andacht des herczen nit da bë̈, so wer das gebet des munds und würcken des leibs wenig nücz (Z. 183f.).

Der im Einklang von Mund, Werk und Herz vorgeführte gaistliche gesang wird schließlich in seiner erlösenden Wirkung veranschaulicht. Der Prediger erinnert dabei an eine Episode im alttestamentlichen Buch der Könige, genauer: im ersten Buch Samuel (I Sm 16,15/23): Als König Saul von einem bösen Geist besessen war, erfuhr er durch Davids Harfenspiel Linderung in seiner depressiven Stimmung (Z. 185-188). ${ }^{34}$ Angesichts ihrer Plastizität kommt diese biblische Szene der Anschaulichkeit eines Exempels recht nahe. In der >Predigt vom heiligen Geist< dient die therapeutische Erquickung von Davids Harfenspiel dazu, die erlösende Kraft des durch Herz, Mund und Werke vollzogenen Gotteslobs zu verdeutlichen. Die Folgerung lautet: wann wir gott loben, so mach wir auch den bösen gaist flüchtig von uns (Z. 188f.). Ein Vers aus dem Jakobusbrief (Iac 4,7) bestätigt zuletzt die Wirkmächtigkeit andächtigen Gebets gegenüber den Anfechtungen von Schwermut und schlechter Gesinnung.

Im Anschluß an die Betrachtung der beiden Textabschnitte gilt es, die Funktionsweise der Artes-Auslegung zu hinterfragen: Was haben die Artes-Deutungen der Logik und Musik gemeinsam? - Einige strukturelle Parallelen sind doch recht auffällig. Beide Disziplinen werden in ihren je spezifischen Artikulationsformen vorgeführt - Artikulationsformen, die alsbald in den Dienst einer moralisierenden Auslegung treten. Die Disputation als typische Sprechweise der Ars logica lehrt Weltverachtung, lehrt den Verzicht auf Fleischeslust, Weltgenuß und schlechte Gesinnung. Die Dreistimmigkeit der mittelalterlichen Motettenkunst als Ausdrucksform der Ars musica zielt auf devotionale Praxis, hält an zu

\footnotetext{
${ }^{33}$ Terminologie: tenor - motetus - triplum (Johannes de Grocheo, um 1300); tenor - medius cantus - tertius cantus (Walter Odington, frühes 14. Jh.). Vgl. FinsCHER, Motette [Anm. 32], Sp. 638; FinsCHER/LAUbenthal, Cantiones [Anm. 32], S. 285.

${ }^{34} \mathrm{Vgl}$. GÜNTER BANDMANN, Melancholie und Musik. Ikonographische Studien (Wissenschaftliche Abhandlungen der Arbeitsgemeinschaft für Forschung des Landes Nordrhein-Westfalen 12), Köln/Opladen 1960, S. 11-21; WALTER SALMEN, König David - eine Symbolfigur in der Musik (Wolfgang Stammler Gastprofessur für Germanische Philologie. Vorträge 4), Freiburg/Schweiz 1995, S. 14f.; DAGMAR HOFFMANN-AXTHELM, David als 'Musiktherapeut'. Über die musikalischen Heilmittel Klang - Dynamik - Rhythmus - Form, in: König David - biblische Schlüsselfigur und europäische Leitgestalt, hg. von WALTER DIETRICH u. HUBERT HERKOMMER, Freiburg/ Schweiz, Stuttgart 2003, S. 565-588, bes. S. 568f.
} 
Gebet, guten Werken und Andacht. Beide Male unterstützen Exempla den moralischen Impetus der Artes-Deutung: Frau Welt warnt vor dem trügerischen Schein diesseitiger Freude; Davids Harfenspiel gemahnt an die erbauende Kraft des Gotteslobs. Auf diese Weise generiert sich aus spezifischen Diskursarten der Artes-Fächer jeweils eine zweite Diskursformation, jene der moralischen Auslegung.

Wie aber läßt sich dieser Übergang von gelehrten, dem mittelalterlichen Wissenschaftssystem verpflichteten Artikulationsweisen in einen moraliserendhomiletischen Aussagemodus näher beschreiben?

Der Rückgriff auf die Terminologie allegorischer Sinnschichtung ${ }^{35}$ scheint hier nicht ausreichend. Zwar läßt sich das Verhältnis der Artes zu ihrer jeweiligen Auslegung mit der Polarität von buchstäblichem Erstsinn und geistigem Zweitsinn fassen: Künste wie die Logik und Musik stehen im sensus litteralis, ihre Deutung auf Weltverachtung und Devotionalität bildet den sensus spiritualis oder, wenn man spezifizieren möchte, den sensus moralis. Doch ist damit die sich innerhalb des moralisierenden Aussagegestus entwickelnde Eigendynamik der Artes-Interpretation nur unzulänglich erklärt. Gerade diese Eigendynamik aber, die sich ihrer fachwissenschaftlichen Grundlage entledigt, gilt es zu beschreiben. $\mathrm{Zu}$ berücksichtigen ist ferner die allenthalben greifbare, auf moralisches Handeln der Zuhörer gerichtete Wirkungsintention der Predigt. Die Einflußnahme auf die Lebenspraxis der Rezipienten zeichnet sich als fundamentales Anliegen der >Predigt vom heiligen Geist $<$ ab. Beide Aspekte - die Eigendynamik des Aussagegestus und die moralisierende Wirkungsabsicht lassen sich im behutsamen Rückgriff auf diskursanalytisch-linguistische Beschreibungsverfahren angehen.

Es bietet sich in diesem Zusammenhang an, mit Elementen eines DiskursBegriffs zu arbeiten, wie ihn MichEL FOUCAULT in seiner >Archäologie des Wissens< entwickelt hat. ${ }^{36}$ Unter diskursiven Formationen versteht FOUCAULT Wissenszweige wie die Grammatik oder die Medizin, welche in unterschiedlichen historischen Epochen jeweils unterschiedliche Aussagen über wissenschaftliche Gegenstände - wie etwa die Sprache, die Krankheit - anstellen. Die Thematik eines wissenschaftlichen Gegenstands ist auf diese Weise »constituée par l'ensemble de ce qui a été dit dans le groupe de tous les énoncés qui la nommaient, la découpaient, la décrivaient, l'expliquaient, racontaient ses développements, indiquaient ses diverses corrélations, la jugeaient, et éventuellement lui prêtaient la parole en articulant, en son nom, des discours qui devaient passer

${ }^{35}$ Dazu grundlegend FrIEDRICH OHLY, Vom geistigen Sinn des Wortes im Mittelalter, ZfdA 89 (1958), S. 1-23, wieder abgedruckt in: DERS., Schriften zur mittelalterlichen Bedeutungsforschung, Darmstadt ${ }^{2}$ 1983, S. 1-31; BluMENBERG, Die Lesbarkeit der Welt [Anm. 19].

${ }^{36}$ Michel Foucault, L'archéologie du savoir (Bibliothèque des sciences humaines), Paris 1969. Deutsche Übersetzung: Michel FOUCAUlT, Archäologie des Wissens, übers. von UlRICH KÖPPEN (stw 356), Frankfurt ${ }^{5}$ 1992. Vgl. auch MANFRED FRANK, Zum Diskursbegriff bei Foucault, in: Diskurstheorien und Literaturwissenschaft, hg. von JÜRGEN FOHRMANN u. HARRO MÜLlER (stm 2091), Frankfurt 1988, S. 25-44. 
pour être les siens «. ${ }^{37}$ FOUCAULT drängt mit dieser Auffassung auf eine Entkoppelung der diskursiven Formation von ihrem Objekt, ihrem wissenschaftlichen Gegenstand. Er betont, daß Diskurse gerade nicht ein »entrecroisement de choses et de mots $\aleph^{38}$ darstellten. Im Gegenteil seien Diskurse zu behandeln »comme des pratiques qui forment systématiquement les objets dont ils parlent ${ }^{39}{ }^{39}$ Es sind nach dieser Auffassung also nicht die Gegenstände, welche die Anlage diskursiver Formationen bedingen. Vielmehr sei davon auszugehen, daß jeder Diskurs seinen Gegenstand erst schaffe - »qu'à son tour chacun de ces discours a constitué son objet et l'a travaillé jusqu'à le transformer entièrement «. ${ }^{40}$

Vor diesem Hintergrund wird die Eigendynamik beschreibbar, in welcher sich die >Predigt vom heiligen Geist $<$ das Lehrsystem der freien Künste aneignet und unterwirft. Artes-spezifische Gegenstände und Praktiken wie die logische Disputation oder die Polyphonie der Motette werden innerhalb des moralisierenden Aussagegestus der Predigt so abgewandelt, daß sich ihr fachlicher Wert reduziert, ja nahezu disqualifiziert. Im Gegenzug verselbständigt sich die Diskursivität der moralischen Auslegung gegenüber den wissenschaftlichen Zusammenhängen. In der spirituellen Deutung bildet die >Predigt vom heiligen Geist< eine Sprechweise aus, die mit jener, die von den Artes als wissenschaftliche Gegenstände handelt, nicht mehr viel gemein hat.

Welche Funktion aber nehmen dann die sieben freien Künste innerhalb des Textes ein? Zur Beantwortung dieser Frage ist es notwendig, sich der Wirkungsabsicht der Predigt zu stellen. Es bietet sich dabei an, auf Kommunikationsmodelle zurückzugreifen, die in der Erforschung der Predigten Meister Eckharts entwickelt wurden. BURKHARD HASEBRINK und FRIEDRICH IOHN haben hier wichtige Analysestrategien aufgezeigt. ${ }^{41}$ Beide weisen nachdrücklich darauf hin, $\mathrm{da} ß$ es nicht genügt, nur den inhaltlichen Aspekt einer Predigt, in linguistischer Terminologie: deren propositionalen Gehalt, zu erfassen. Vielmehr komme es wesentlich darauf an, die Predigt als einen Vollzug sprachlichen Handelns zu

${ }^{37}$ Foucault [Anm. 36], S. 45; dt. Übers. [Anm. 36], S. 49: »durch die Gesamtheit dessen konstituiert worden, was in der Gruppe all der Aussagen gesagt worden ist, die sie benannten, sie zerlegten, sie beschrieben, sie explizierten, ihre Entwicklung erzählten, ihre verschiedenen Korrelationen anzeigten, sie beurteilten und ihr eventuell die Sprache verliehen, indem sie in ihrem Namen Diskurse artikulierten, die als die ihren gelten sollten «.

${ }^{38}$ FouCAULT [Anm. 36], S. 66; dt. Übers. [Anm. 36], S. 74: »Verschränkung der Dinge und der Wörter«.

${ }^{39}$ FouCAUlt [Anm. 36], S. 67; dt. Übers. [Anm. 36], S. 74: »als Praktiken [...], die systematisch die Gegenstände bilden, von denen sie sprechen «.

${ }^{40}$ FouCAult [Anm. 36], S. 46; dt. Übers. [Anm. 36], S. 50: »daß seinerseits jeder dieser Diskurse seinen Gegenstand konstituiert und soweit bearbeitet hat, daß er ihn völlig transformierte«.

${ }^{41}$ Vgl. BURKHARD HASEBRINK, Das Predigtverfahren Meister Eckharts. Beobachtungen zur thematischen und pragmatischen Kohärenz der Predigt Q 12, in: Die deutsche Predigt im Mittelalter. Internationales Symposium am Fachbereich Germanistik der Freien Universität Berlin vom 3.6. Oktober 1989, hg. von VOLKER MERTENS u. HANS-JOCHEN SCHIEWER, Tübingen 1992, S. 150168; DERS., Formen inzitativer Rede bei Meister Eckhart. Untersuchungen zur literarischen Konzeption der deutschen Predigt (TTG 32), Tübingen 1992; FRIEDRICH IOHN, Die Predigt Meister Eckharts. Seelsorge und Häresie (Beiträge zur älteren Literaturgeschichte), Heidelberg 1993. 
verstehen. Es gelte folglich, die gegenüber dem Zielpublikum intendierten Effekte zu berücksichtigen, d. h. in linguistischer Terminologie: die pragmatische Dimension der Predigt, deren illokutive Funktion, zu erschließen. ${ }^{42}$ Man hat also mit einem bipolaren Schema zu arbeiten, das sowohl dem propositionalen Lehrgehalt der Predigt wie auch deren illokutiver Funktion gerecht wird. Nach BURKHARD HASEBRINK wird die Predigt unter dieser Voraussetzung zum »Modell eines kommunikativen Handelns, das Elemente informativer, appellativer, persuasiver und verheißender Rede zum Zwecke integriert, der Heilserwartung des Rezipienten ein Orientierungs- und Deutungsangebot zur Verfügung zu stellen $\ll .{ }^{43}$ Das sprachliche Handeln des Predigers verfolgt mithin das Ziel, seinerseits auf das Handeln des Publikums einzuwirken. Diese Auffassung läßt sich im übrigen auch in Äußerungen der mittelalterlichen Ars praedicandi greifen, wo Predigt definiert wird als eine auf die Handlungsweise einer Zuhörerschaft ausgerichtete Unterweisung (pluribus facta persuasio ad merendum).$^{44}$

Im Falle der >Predigt vom heiligen Geist $<$ deckt sich der propositionale Gehalt weitgehend mit jenem Aussagemodus, den FouCAUlT >diskursive Formation< nennt: Vorgeführt werden die Artes liberales nicht in ihrem wissenschaftlichen Status, sondern in einer spirituellen Interpretation. Die illokutive Funktion besteht dabei darin, die einzelnen Künste als Anweisung zum moralischen, heilsgarantierenden Handeln zu instrumentalisieren.

Diese in der >Predigt vom heiligen Geist < faßbare Wirkungsabsicht läßt Rückschlüsse auf das vom Verfasser anvisierte Zielpublikum zu. Die Rezipientenschaft dürfte wohl kaum im schriftkundigen Milieu einer höheren Schule oder Universität zu suchen sein. Vor einem gebildeten Universitätspublikum würde die zu Lasten fachlicher Inhalte vorgenommene Spiritualisierung der Artes wenig Beifall finden. Wie man in einem gelehrten Umfeld über die Wissenschaften predigt, bezeugt eine am 25. November 1396 zum Festtag der heiligen Katharina (Patronin der Artistenfakultät) vorgetragene Rede des Heinrich von Langenstein, der als Neuorganisator und Rektor der Universität Wien tätig war. ${ }^{45}$ Die in lateinischer Sprache abgefaßte Predigt behandelt Ursprung, gegenseitige Ver-

${ }^{42}$ Vgl. HASEbRINK, Predigtverfahren [Anm. 41], S. 152f.; DERS., Formen inzitativer Rede [Anm. 41], S. 36-43; IoHN [Anm. 41], S. 48-59.

${ }^{43}$ HASEBRINK, Formen inzitativer Rede [Anm. 41], S. 265.

${ }^{44}$ Robertus de Basevorn, >Forma praedicandi<, Cap. I, zit. nach CHARLAND [Anm. 16], S. 238. Vgl. auch HASEBRINK, Formen inzitativer Rede [Anm. 41], S. 36; FrIEDRICH IOHN, Rez. zu: Die deutsche Predigt, hg. von Mertens/SchiEwer [Anm. 41], ZfdA 123 (1994), S. 243-248, hier S. 247.

${ }^{45}$ Vgl. Thomas Hohmann/Georg KreuZer, Heinrich von Langenstein, ${ }^{2}$ VL III, Sp. 763-773. Zur Predigt >De sancta Catharina< kurz ebd., Sp. 766. Ausführlicher: AlBERT LANG, Die Katharinenpredigt Heinrichs von Langenstein. Eine programmatische Rede des Gründers der Wiener Universität über den Aufbau der Glaubensbegründung und die Organisation der Wissenschaften. I. Text, Divus Thomas (Freiburg/Schweiz) 26 (1948), S. 123-159; DERS., Die Katharinenpredigt ... II. Charakter und Aufbau [Anm. 16]; DERS., Die ersten Ansätze zu systematischer Glaubensbegründung, Divus Thomas (Freiburg/Schweiz) 26 (1948), S. 361-394; DERS., Die Universität als geistiger Organismus nach Heinrich von Langenstein, Divus Thomas (Freiburg/Schweiz) 27 (1949), S. 41-86; WiLLIAMS [Anm. 6], S. 397f. 
flechtung und Hierarchie der Wissenschaften. Aus der Ordnung der Disziplinen wird die Gliederung der Universitäten abgeleitet. Den Anfang machen die Artes, es folgen Medizin und Jurisprudenz, an der Spitze steht die Theologie.

Die >Predigt vom heiligen Geist $<$ trennen Welten von derartigen Überlegungen zur Wissenschaftstheorie und zur Organisation des Studiums. Gleichwohl unterstellt die Predigt eine rudimentäre Vertrautheit mit den Artes. Sie setzt Kenntnisse zur Anordnung von Trivium und Quadrivium voraus und rechnet mit einem fachlichen Kernwissen, das sich auf dem schlichten Niveau von Merkversen bewegt. Lateinische Merkverse zu den Artes liberales lassen sich in Handschriften seit dem frühen Mittelalter belegen ${ }^{46}$ Sie sind auch noch im 15. Jahrhundert weit verbreitet ${ }^{47}$ und begegnen zu dieser Zeit außerdem in volkssprachlichen Fassungen. Ein deutscher Merkvers zur Logik lautet etwa: Mit arguiern vnd disputÿrn kan ich waur vnd falsch erkÿrn. Und von der Musik heißt es: Jch ler singen vnd notÿrn vnd dar zu kunschtlich discantÿrn. ${ }^{48}$

Minimalwissen dieser Art verweist auf ein halbgebildetes, halbalphabetisches Publikum. Faßbar wird eine Rezipientenschaft, die sich innerhalb der Volkssprache und allenfalls am Rande gelehrter Latinität bewegt, eine Rezipientenschaft mithin, die im Grenzbereich schriftlicher und mündlicher Wissensvermittlung angesiedelt ist und schriftkundiger Vermittlerpersönlichkeiten bedarf. ${ }^{49}$ Man wird an ein klösterliches Mischpublikum zu denken haben, das bestenfalls über einfache Grundkenntnisse mittelalterlicher Gelehrsamkeit verfügt. Eine solche Zielgruppe aber dürfte gerade in den benediktinischen Reformklöstern an-

${ }^{46}$ Vgl. die Zusammenstellung bei STOLZ, Artes-liberales-Zyklen [Anm. 7], Anhänge 1-3, S. 676682 .

${ }^{47}$ Vgl. zum Beispiel die Hinweise bei Michael StOlz, Körper und Schrift. Wissensvermittlung im >Psalterium glossatum< von Wilhelm Müncher (1418), in: Die Vermittlung geistlicher Inhalte im deutschen Mittelalter. Internationales Symposium Roscrea 1994, hg. von TIMOTHY R. JACKSON, Nigel F. Palmer u. Almut Suerbaum, Tübingen 1996, S. 97-117, hier S. 107f.

${ }^{48}$ München, BSB, Clm 3941 (2. Drittel d. 15. Jh., Sigismund Gossembrot, Augsburg), fol. 18 (Logik), fol. 17 (Musik). Vgl. zur Handschrift: KARL-AUGUST WIRTH, Neue Schriftquellen zur deutschen Kunst des 15. Jahrhunderts. Einträge in einer Sammelhandschrift des Sigmund Gossembrot (Cod. lat. mon. 3941), Städel-Jahrbuch NF 6 (1977), S. 319-408; Katalog der deutschsprachigen illustrierten Handschriften des Mittelalters, begr. von Hella FrÜHMORGEN-Voss, fortgef. von NORBERT H. OTT [u. a.] (Veröffentlichungen der Kommission für deutsche Literatur des Mittelalters der Bayerischen Akademie der Wissenschaften), Bd. 1, München 1991, Nr. 9.2.4., S. 301f.; Stolz, Artes-liberales-Zyklen [Anm. 7], S. 331, 334-339, 578-622, und Anhänge 7, 8, S. 733-751. - Ähnlich Cambridge (Mass.), Harvard University, The Houghton Library, Ms. Ger. 74 (ca. 1460/70, schwäbisch-alemannisch), fol. 21 $1^{v}$ : Mit arguieren vnd disputieren kan ich war vnd falsch erkieren. - Jch leren singen vnd notieren vnd darzu künstlich discantieren. Zit. nach ECKEHARD SIMON, Priamel, short verse poems, and proverbs from the Houghton Codex Ms. Ger. 74 (ca. 1460/70). Variants and unpublished texts, Michigan Germanic Studies 2 (1976), S. 21-34, hier S. 27f. Zur Handschrift DERS., Eine neuaufgefundene Sammelhandschrift mit Rosenplüt-Dichtungen aus dem 15. Jahrhundert, ZfdA 102 (1973), S. 115-133; STOLZ, Artes-liberales-Zyklen [Anm. 7], S. 614f. und Anhang 8, S. 749-751.

${ }^{49}$ Zur Funktionsweise solcher aus Analphabeten und Schriftkundigen zusammengesetzten Textgemeinschaften vgl. BRIAN STOCK, Medieval Literacy, Linguistic Theory, and Social Organization, New Literary History 16 (1984), S. 13-29; DENNIS H. GREEN, Medieval Listening and Reading. The primary reception of German literature 800-1300, Cambridge [usw.] 1994, S. 285 f. 
zutreffen sein: Als mögliche Adressaten geraten hier neben Klerikern vor allem Laienbrüder und -schwestern (Konversen) mit divergierenden Bildungsvoraussetzungen in den Blick. ${ }^{50}$

Die freien Künste werden in diesem Milieu nicht systematisch behandelt. So beschränkt sich denn in der >Predigt vom heiligen Geist< die Abfolge der Artes darauf, lediglich ein Gerüst für die Vermittlung heterogener, den Artes primär nicht zugehöriger Inhalte zu liefern. Die freien Künste fungieren als Subsystem, auf dem sich die Übermittlung moralischer Anweisungen aufbaut. Ihnen kommt damit wenig mehr zu als die Rolle von einprägsam strukturierten Memorialzeichen, mittels derer sich die Anleitungen zu religiöser Vervollkommnung speichern lassen. ${ }^{51}$ Die Artes-Reihe erweist sich als memorierbares Gliederungsprinzip, das den Predigtvortrag kommunikationstechnisch unterstützt: Sie erleichtert dem Prediger die Vermittlung der moralischen Anweisungen und hilft den Adressaten bei deren Befolgung. In dieser memorativen Zeichenfunktion aber wären die Künste einigermaßen beliebig austauschbar und könnten ersetzt werden durch Ordnungsmuster, die eine vergleichbar markante Konventionalität aufweisen.

Eine anschauliche Alternative hält die >Predigt vom heiligen Geist $<$ selbst bereit: Jener Schlußteil, der den anfangenden Menschen das Buch des Erdreichs zum Studium unterbreitet, liefert eine Ausdeutung der vier Evangelistensymbole im Anschluß an die Vision von Ezechiel ${ }^{52}$ (Z. 259-269):

Wie aber der gaystlich leben söll, lert der hä̈lig gaist in der gesicht die ezechiel sach. Der selbig sach die antlüt der vier evangelisten, des ainen in gestalt ains menschen, des andern in gestalt ains leo, des dritten in gestalt ains ochsen, des vierden in gestalt ains adlers. Alz ob der haÿlig gaist spräch: Wölcher in gott zü nemen will, der sol haben ain antlüt des menschen in der gemain, also das er miltsamlich diemütiklich und fridsamlich wandel mit allen menschen. Im dormiter sol er haben ain antlüt des leon also das er keck së̈ im widerstan den begirlichä̈tten und versüchungen. Im refecter sol er haben das antlütt des ochsen, also das er kostlicher und zartter speis nit achte.

${ }^{50}$ Vgl. BARBARA FrANK, Konversen und Laien in benediktinischen Reformklöstern des 15. Jahrhunderts, in: Ordensstudien I: Beiträge zur Geschichte der Konversen im Mittelalter, hg. von KASPAR Elm (Berliner Historische Studien 2), Berlin 1980, S. 49-66; Klaus SchreINER, Gebildete Analphabeten? Spätmittelalterliche Laienbrüder als Leser und Schreiber wissensvermittelnder und frömmigkeitsbildender Literatur, in: Wissensliteratur im Mittelalter und in der Frühen Neuzeit. Bedingungen, Typen, Publikum, Sprache, hg. von Horst BRUNNER u. NORBERT RICHARD WOLF (Wissensliteratur im Mittelalter 13), Wiesbaden 1993, S. 296-327; NIEDERKORNBRUCK [Anm. 22], S. 69, 110-116; BAUER [Anm. 12], S. 9-28.

${ }^{51} \mathrm{Vgl}$. zur Rolle gedächtnisunterstützender Praktiken in der mittelalterlichen Predigt FRANCES A. YATES, The Art of Memory, London 1966, S. 84-86, 96-98; MARY CARRUTHERS, The Book of Memory. A Study of Memory in Medieval Culture, Cambridge [usw.] 1990, S. 103-106, 206211.

${ }^{52}$ Vgl. Ez 1,10 und 10,14 sowie die exegetische Tradition, etwa Hieronymus, Prolog des MtKommentars >Plures fuisse $<$ (S. Hieronymi Presbyteri Commentariorum in Matheum libri IV, hg. von D. HuRst/M. AdRIAEN, in: S. Hieronymi Presbyteri Opera I,7 (CC 77), Turnhout 1969, S. 1-6, hier S. 3f.). Zum weiteren Traditionshorizont U[RSULA] NILGEN, Evangelisten und Evangelistensymbole, LCI I, Sp. 696-713, bes. Sp. 696; DIES., Evangelistensymbole, RDK VI, Sp. 517-572, bes. Sp. 517-519. 
Im kor oder kirchen sol er haben ain antlüt des adlers, also das er in seinem gemüt und andacht erhöcht werd in gott.

Die vier von Ezechiel geschauten Wesen vermitteln hier Verhaltensregeln für das Leben im Kloster und werden bestimmten räumlichen Sphären zugewiesen: Die Gestalt des Menschen steht für korrektes Verhalten in der Gemeinschaft, der Löwe für den Widerstand gegen sinnliche Begierde im Schlafsaal, der Stier warnt vor übermäßigem Appetit im Refektorium, der Adler schließlich repräsentiert die geistige Erhebung in der Kirche. Illustrative Ordnungsmuster wie die Vierzahl der Evangelistensymbole oder die Siebenzahl der freien Künste kommen den Zuhörern dabei zugute, die moralischen Anweisungen zu verinnerlichen und sie im täglichen Verhalten zu beherzigen.

Im Rückblick auf die angestellten Betrachtungen läßt sich folgendes Fazit ziehen:

Die >Predigt vom heiligen Geist< bietet eine Moralisierung der Künste im Sinne religiöser Vervollkommnung. Es handelt sich dabei um mehr als eine bloß spirituelle Auslegung der Artes. Die Deutung der sieben freien Künste bildet eine eigene Diskursivität aus, die sich des wissenschaftlichen Artikulationssystems zwar bedient, dieses aber zugleich hinter sich läßt. Die Sprechweise der Predigt ist als sprachliches Handeln aufzufassen, mit dem der Prediger seinerseits auf das Handeln seiner Zuhörerschaft einzuwirken versucht. Die Artes fungieren dabei in ihrer konventionellen Ordnungsstruktur als Memorialzeichen, die den Rezipienten eine Befolgung der moralisierenden Deutung erleichtern.

Einzelheiten, wie eine inhaltliche Gliederung, die der Aufnahmekapazität des Publikums Rechnung trägt, oder die auf Minimalwissen reduzierten Inhalte der Künste verdienen nähere Beachtung und weiteres Nachdenken. Sie deuten hin auf eine Vermittlung der Predigt in mündlichen Gebrauchszusammenhängen oder jedenfalls am Rande der Schriftlichkeit. Fragt man nach dem historischen Ort der Predigt, ihrem Sitz im Leben, so zeichnet sich ein klösterliches Milieu ab, in dem sich Kleriker und Laien begegnen - dies etwa im Gegensatz zu einem universitären Bildungszentrum. Die Anleitung zu religiöser Vervollkommnung im klösterlichen Rahmen sowie die handschriftliche Überlieferung liefern Indizien dafür, daß die >Predigt vom heiligen Geist $<$ als seelsorgerisches Instrument der Melker Reform gedient haben könnte.

\section{Text}

$>$ Predigt vom heiligen Geist<

Der Textabdruck folgt Handschrift A (München, BSB, Cgm 830, fol. 187 ${ }^{\mathrm{v}}$ $\left.200^{v}\right) .{ }^{53}$ Abbreviaturen sind stillschweigend aufgelöst, Supraskripta werden bei-

\footnotetext{
${ }^{53} \mathrm{Vgl}$. zur Überlieferung und zu den verwendeten Siglen oben, S. 57f.
} 
behalten. Schaft- $\int$ in der Handschrift wird normalisiert zu $s, v$ zu $u$, Diphthong $\stackrel{a}{a}$ zu $a u, j$ vor Konsonant zu $i$. Um die Lesbarkeit zu erleichtern, werden Großschreibung (bei Satzanfängen, Eigennamen) und Interpunktion nach modernen Gesichtspunkten eingerichtet; Absatzgliederung wird nach Sinnabschnitten eingeführt. Doch gehen diese editorischen Maßnahmen oft mit dem Gebrauch der Handschrift (Majuskeln, Gliederungsmittel wie Virgeln, Litterae notabiliores, Absatzzeichen, Randnotizen) konform. Seitenwechsel im Manuskript wird durch entsprechende Blattangaben in Kursivdruck angezeigt. Kursivdruck innerhalb des edierten Textes verweist auf Emendationen, Erläuterungen finden sich im Apparat.

Der Apparat selbst ist zweiteilig angelegt:

1. Der kritische Apparat verzeichnet die Randnotizen in A und sonstige Schreiberzusätze in den Handschriften (unberücksichtigt bleiben einige Randeinträge des 16. Jhs. in M). Der kritische Apparat enthält ferner die Überlieferungsvarianten mit der Angabe von Handschriftensiglen; die Schreibweise der Textzeugen wird weitgehend beibehalten (einige wenige nicht darstellbare Sonderzeichen werden in Kursive aufgelöst). Verzeichnet werden morphologische, lexematische und syntaktische Abweichungen, nicht jedoch Lautvarianten wie gand - gend, reichtum - reichtung. Grenzfälle werden jeweils mit aufgenommen; so beispielsweise die Varianten rüwen - rüen - rüen (nach mhd. riuwen oder ruowen), die Varianten zu letz(i)gen (Lehnwort nach lat. lectio), die Varianten leren - lernen (beide in der Regel für >docere< gebraucht). Klammersetzung wie (B) zeigt an, daß die Handschrift mit dem angegebenen Text in Wortwahl und Syntax, nicht jedoch im Wortbild (Schreibung, Abkürzungen, Lautvarianten) übereinstimmt. Angaben vor der eckigen Klammer (]) verweisen auf den edierten Text (in der Regel nach A, dann jeweils ohne Siglevermerk; eigens vermerkt werden jedoch die mit A übereinstimmenden Handschriften); Angaben hinter der eckigen Klammer enthalten die Überlieferungsvarianten. Bei Emendationen (Kursive im edierten Text) stehen die gegen A befolgten Handschriften vor der Klammer, die Fassung von A und ggf. weitere Überlieferungsvarianten dahinter.

2. Der Quellenapparat verzeichnet identifizierte Vorlagen und Parallelbelege, deren Text jeweils in Anführungszeichen gesetzt wird. Ein umfassender Kommentar kann im Rahmen dieses Tagungsbands nicht geleistet werden und bleibt einem späteren Forschungsstand vorbehalten. Zur Quellensuche wurde auf Computer-Datenbanken (Patrologia Latina Database, CETEDOC) und konventionelle Hilfsmittel wie Indices, Konkordanzen zurückgegriffen. Für Hinweise auch zum Ausschluß bestimmter Quellenbereiche - danke ich Klaus Klein (Marburg), Nigel F. Palmer (Oxford), Regina D. und Hans-Jochen Schiewer (Freiburg i. Br.), Ulla Williams (Augsburg). 


\section{[fol. $\left.187^{\vee}\right]$ Ain gůtte predig von dem hayligen gaist}

Wann nun kompt der gaÿst der warhaÿt, so wirtt er eüch lernen alle warhä̈t, Johannis xvi.

Es spricht Dÿonisius also: Wann ich ganczes wesen der geschöpfft mit 5 scherpff meins gemütz an sich, so vind ich das ain ÿedlich sach so vil volkommer ist, alz vil sÿ irem anfang nächer und geleucher ist. Dann volkommenhaÿt der geschöpfft ist ettwas geleichnuß des anfangs, von dem sy sind. Alz wir sechen, wann ÿe nächer ain planet der sunnen ist, ÿe scheinender er ist. Und ÿe nächer die bäch des brunnen send dem ursprung, ye clarer wasser. Und nun gott 10 ist ain anfang, mittel und end aller sach, alz da spricht der zwöllffbott: Auß im seÿen wir, durch in leben wir, in in alz in unser lestes end seÿen wir geordnet, darumb ÿe nächer ain mensch gott ist mit gemüt und dem [fol. $\left.188^{r}\right]$ gaist, $\ddot{\mathrm{y}}$ volkommer er ist.

Dann es sprich Sant Augustin: Gott will dich nit haben alz du bist, sunder alz 15 du sein solt. Sprichest aber wie sol ich sein, ich sprich: ain cristan von Cristo und ainer mit gott. Also was gott wöll, dz du das auch wöllest, und das dein will zů gemessen seÿ dem willen gotz nach deiner vermüglichä̈t und nach deiner erkanttlichait und nach deiner begirlichait.

Zů dem ersten nach deiner vermüglichä̈t. Dann alles das, das Cristus umb 20 unsers haÿls willen hatt mügen tủn, hatt er getan. Also sol auch unser will sein, das wir tüwen, das wir tůn mügen. Bernhardus spricht: Wann der mensch tůt das

1 Dieselbe Überschrift auch in BGM, Aÿn köstlichi predig $N$, Überschrift fehlt in $S .2$ Wann $B G(N) S$ ] Banen $M$. gaÿst $(B G M N)]$ geyst verbessert aus $\operatorname{trostr}^{\mathrm{s}} S$. lernen $B G(S)$ ] leren $M N$. 3 Randnotiz A: Johannis. Johannis xvi $(G N)]$ fehlt $B, \overline{1}$ crist $^{9}$ iesus $M$, Johñis Am xvj $S$. 4 Randnotiz $A$ : Dyonisius. ganczes $(B) G M]$ gancz $N$, das gantz $S$. 4f. mit scherpff meins gemütz an sich $(B G M)]$ an sich mit scherpf meins gemütes $N S . \quad 8$ ist $B G M N]$ ist stett $S . \quad 9$ send dem ursprung $(B G M N)]$ dem vrsprūg sind $S$. clarer wasser $(G M)$ ] clärer vnnd geschmacher wasser $B(N S)$. Und nun $(B G) M]$ Seid nun $N(S) . \quad 10$ Randnotiz $A$ : Apostolus. alz da $(B G M)]$ dañ es $N(S) . \quad 11$ in in $B(G) M(N)] \mathrm{Jn}$ jm $S . \quad 12$ mit gemüt und dem gaist $(G M)]$ mit dem gemütt vnnd dem gaist $B$, mit můt vñ dē gaist $N$, mit dem gemüt vnd gaist $S .14$ Randnotiz A: Augustinus. 16 wöll $B G M(N)]$ will $S . \quad 17$ zů gemessen seÿ $B(N S)$ ] seÿ zů gemessen $G(M)$. vermüglichaÿt und $(B G M)]$ v'müglichait $N(S)$. 20 tůn, hatt $(B G M)]$ tůn $\mathrm{dz}$ hat $N$, gethůn das hat $S$. 21 Randnotiz A: Bernhardus. 21f. das er mag $(G) M(N)]$ was er mag $B$, das er thůn mag $S$.

2 Wann nun ... warhaÿt Io 16,13. 4-6 Wann ich ... geleucher ist Vgl. Ps.-Dionysius Areopagita, Dionysiaca, I, Brügge 1937, De divinis nominibus (Übers. Joh. Sarracenus), V,3, S. 331: »Et est sicut arbitror hoc verum quod magis uno et infiniti doni Deo participantia, magis ipsi sunt propinqua et diviniora derelictis«. 9f. gott ist ... aller sach Vgl. ebd., V,8, S. 354: »omnium substantificator et principium et medietas et finis«; ferner Ps.-Meister Eckhart, Deutsche Mystiker d. 14. Jhs., hg. von F. Pfeiffer, Bd. 2, Leipzig 1857, S. 531, Z. 2f.: »Her über sprichet Dionysius: got ist ein anevanc und ein mitel und ein ende aller dinge«. $\quad$ 10f. Auß im seÿen wir IIo 4,6 u. 5,19. 11 durch in leben wir Vgl. I Io 4,9. in in ... geordnet Vgl. I Io 4,15f. (?). 14f. Gott will ... solt Vgl. Augustinus, Enarrationes in Psalmos, CC 39, Ps. 99, § 5, S. 1395, Z. 50f.: »Es iniquus, esse debes iustus«; Augustinus, Sermo >De duobus temporibus<, Revue Bénédictine 79 (1969), S. 64, Z. 21: $»$ Prius tibi displiceat quod es, ut possis esse quod non es«; Augustinus, Sermones de sanctis, Sermo 315, Cap. VI,9, PL 38, Sp. 1430: »melius hoc dico quod te esse volo, quam quod es«. 
er mag, so wirt er entschuldiget in dem das er nit mag. Und darumb so süllen wir tůn, $\mathrm{dz}$ wir mügen, und dz ander behalten dem verdienen Cristi, dem da müglich ist das, dz ÿederman unmüglich [fol. $\left.188^{v}\right]$ ist.

Züm andern süllen wir unsern willen dem willen gotz geleich machen nach 25 unser erkanttlichaÿt. Dann Cristus hatt alles das getan, das er erkantt nücz sein unserm haÿl. Also sol auch unser will sein schnell zủ allem dem, das er erkennt gụtt sein. Und was gott wöll, das wir das auch wöllen, und was er nit wöll, das wir das auch nit wöllen.

Zů dem dritten nach unser begirlichaÿt. Dann Cristus hatt begirlich begert 30 unser haÿl, das darumb blůttiger schwaÿß auß ganczem seinem leib geflossen ist. Also auch sol unser will begern die gerechtikaÿt gotz verbracht werden. Also ob der mensch hundert jar lepte, das er allweg durstig und hungerig wär zů der gerechtikaÿt gotz und nümer spräch, es ist genůg.

Und dz ze tůn und den willen gotz zủ erfüllen, lert uns der haÿlig gaÿst, als 35 dann sprechend die fürgenommen wort: Wann nun kompt etc.

Sant Augustin spricht: [fol. $189^{r}$ ] Ware gaÿstlichaÿt ist ain schủl aller tugend und zucht, in der die gûtten gaÿstlichen leüt sich übend als lang, bis das sÿ volkomenhaÿt begreÿffend. In derselben schủl der haÿlig gaÿst schủlmaister ist. Als nun in den schůlen ettlich wol lernend, ettlich wenig, ettlich gar nichtzt, also ${ }_{40}$ in der gaÿstlichaÿt übend sich ettlich wol in gott, ettlich ain wenig, ettlich gar nichtzt, sunder gand sÿ mer hinder sich, als die die wol angefangen hand und das angefangen gůt verland. Es spricht Sant Augustin: Als ich nit gesechen han bessre menschen dann in der gaÿstlichait, also han ich auch nit bösre gefunden. Und darumb: alz die studenten die nichtz lernend, schämend sich vor iren frain- ${ }_{45}$ den, also werdent die, die in gaÿstlichem schein lebend und nichtzt in gott lernend, geschäntt am jungsten gericht. Wann sÿ wer[fol. $\left.189^{v}\right]$ dent sechen, das sÿ so kostpärlich erlöst sind worden mit dem plùt Cristi und da undanckpär gefunden send.

22 Und darumb so süllen $(B) G M(N)]$ Dar vmb süllen $S . \quad 23 \mathrm{dz}$ wir $(B G M S)$ ] was wir $N$. dem da $B G(M)]$ dē $N(S) . \quad 24$ das, dz $(B G M N)]$ das $S . \quad 25$ dem willen gotz geleich machen $(G M N)$ ] den willen gotz geleich machen $B$, geleich machē dem willē gotz $S .27$ sein schnell $B(G) M(N)$ ] snell sein $S$. 27f. zů allem ... gůtt sein $(B G M)$ ] zw allē dem dz er erkent sein $N$, fehlt $S . \quad 28$ nit wöll $B G M(N)]$ nit will $S . \quad 30$ begirlich $B G M]$ so begirlich $N S . \quad 32$ sol $B G M S]$ so $N . \quad$ begern $(B G M)]$ begerē daz $N(S)$. verbracht $(G M N)]$ vorbracht $A$, volpracht $B S . \quad 33$ lepte $(B G N)]$ lebet $M S$. 33 wär zů $(B G M)$ ] werd nach $N$, wär nach $S$. 34 ist genůg $(G M) N(S)]$ wär genùg $B$. 37 Randnotiz A: Augustinus. 39 volkomenhaÿt begreÿffend $(B G M)]$ volkōmē werdn̄t $N(S)$. schůl $(B G) M(S)$ ] schůl da $N . \quad 40$ lernend $(G N S)$ ] lerent $B$, lerēnt $M .41$ ettlich wol $B G(M) N$ ] wol $S . \quad 42$ gand sÿ $B(G) M(N)]$ sy gendt $S . \quad$ die die $B G M N$ ] die $S .43$ Randnotiz $A$ : Augustinus. $\quad 44$ gefunden $B G M]$ fundñ $N(S) . \quad 48$ da $B G M S$ ] darvm̄ $N . \quad 49$ gefunden $G M(N S)]$ fünden $B$.

37f. schůl aller tugend ... übend Vgl. Alardus Gazaeus, Kommentar zu den Collationes des Johannes Cassianus, PL 49, Sp. 967 C: »cujusmodi (sc.: taciturni) sunt viri religiosi, qui in schola virtutum continue se exercent «. 43f. Als ich ... gefunden Augustinus, Epistula 78,9, CSEL 34, Bd. 2, S. 344, Z. $16-S .345$, Z. 1: »quo modo difficile sum expertus meliores, quam qui in monasteriis profecerunt, ita non sum expertus peiores, quam qui in monasteriis ceciderunt«. 
50 Das wir nun in gott lernen und zůnemen, so lert uns der haÿlig gaÿst die sÿben freÿen künst gaÿstlich zů verstan. Dann zů dem ersten so lert er uns durch die Gramatick leben in rainikaÿt der gewissen. Zủm andern durch Loÿcam lert er uns die welt verschmächen und fliechen. Züm dritten lert er uns durch Rethorick under gott in gemüt und dem gaÿst gediemütiget werden. Zům vierden durch

55 Musick lert er uns diemütiklich betten. Zủm fünfften durch Arismetricam lert er uns zelen die gůttät gotz und darumb danckpar sein. Zům sechsten durch Geometrÿ lert er uns messen ÿrdische ding und hÿmlische. Züm sÿbenden durch Astronomÿ lert er uns nachvolgen dem leben der haÿligen vätter. Und in den dingen [fol. $190^{r}$ ] stät gancze volkommenhaÿt cristenlicher gaystlichaÿt.

${ }_{60} \quad$ Zủ dem ersten lert uns der haÿlig gaist Gramatick, die da ist ain grundfest aller kunst, dann sÿ lert lesen verstan und ordenlich reden. Also auch der haÿlig gaÿst lert uns zům ersten rainikaÿt der gewissen, die da ist ain anfang und zierd aller tugend.

Dann es spricht der zwölffbott: Gott hatt uns ausserwelt vor schaffung der ${ }_{65}$ welt, das wir vor seiner gegenwirtikait haÿlig und unvermäligt wären. Sant Bernhart spricht: Vil sủchent kunst, aber wenig die lauttern gewissen, wie wol doch die gewissen ist die best kunst. Sant Augustin spricht: Unsälig ist der mensch, der vil kan und gott nit waist durch unrainikait seiner gewissen. Es spricht aber Sant Augustin: Es ist nit kostpärlicher noch edler schacz, dann ain 70 raine gewissen, in der [fol. $\left.190^{v}\right]$ seÿdemal gott wonet, so ist nichtzt das den menschen betrüben müg.

50 lert $B]$ lernt $G M N(S) . \quad 51$ zů verstan $(B G M)]$ vständn $N(S) . \quad$ Dann zů dem $(B G M)]$ Dañ zw̄ $N$, Zum $S . \quad$ lert $B G S$ ] lernt $M N . \quad \mathbf{5 2}$ Randnotiz A: Gramatick. Randnotiz A: Loÿck. lert $B G S]$ lernt $M N . \quad 53$ Randnotiz $A$ : Rethorick. $\quad$ lert $B G M S]$ lernt $N . \quad$ durch Rethorick $(M N)]$ durch Rethoricam $B G$, rethorick $S . \quad 54$ und dem $(B) G M]$ vñ $N(S)$. 54f. durch Musick lert er uns $(M)$ ] durch Musicam lert er vnns $B(G)$, lernt er vns durch musick $N$, lernet er vns musick $S$. 55 Randnotiz A: music. Randnotiz A: arismetrick. Zům fünfften $(B N S)]$ Zum fủnfftē mal $G(M)$. durch Arismetricam $B G(N S)$ ] durch arismetrica $M . \quad$ lert $B G M S$ ] lernt $N . \quad 56$ uns $(B) G M N S]$ und $A$. 56f. Randnotiz A: Geometrÿ. durch Geometrÿ $(G M)$ ] durch Geometriam $B$, durch geometrey $N$, geometrey $S . \quad 57$ lert $B G M S]$ lernt $N . \quad$ ÿrdische ding $(B G M)]$ yrdische $N(S)$. und hÿmlische (B)] fehlt $A G M$, vñ himlische ding $N(S)$. 57f. durch Astronomÿ $(M)$ ] durch Astronomia $B$, durch Astronomey $G(N S) . \quad$ Randnotiz A: Astronomi. $\quad 58$ lert BGMS] lernt $N . \quad 60$ Randnotiz A: de gramatica. Zů dem $(B G M)]$ Zum $N S$. lert $B G M S]$ lernt $N$. Gramatick $G(M N S)$ ] Grammatica $B . \quad 61$ aller kunst $M(N S)$ ] aller künst $(B) G$. lert $B G]$ lernt $M N(S)$. haÿlig $(B G N S)$ ] gaistlich $M .62$ lert $B G M S]$ lernt $N . \quad 64$ Randnotiz $A$ : Apostolus. $\quad$ vor schaffung $B G M(N)]$ vor der beschaffung $S . \quad 65$ das wir vor seiner gegenwirtikait hä̈lig und unvermäligt wären $(B G M)$ ]

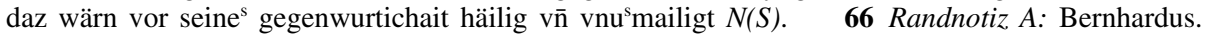
wie wol $B G M$ ] wie NS. 67 Randnotiz A: Augustinus. 68 durch $B G N S$ ] du such $^{\mathrm{s}}$ durch (bei Zeilenwechsel) $M .69$ Randnotiz A: Augustinus. $\quad$ nit $B G M N]$ nichtz $S$. edler $B G M N(S)]$ edlel A. $\quad \mathbf{7 0}$ seÿdemal $B(G M N)]$ fehlt $S . \quad \mathbf{7 1}$ müg $(B G) M]$ mag $N S$.

64f. hatt uns ... wären Eph 1,4. $\quad \mathbf{6 6}$ Vil sůchent ... gewissen Ps.-Bernhard v. Clairvaux, Tractatus de interiori domo seu de conscientia aedificanda, Cap. X,17, PL 184, Sp. 516 B: »Multi quaerunt scientiam; pauci vero conscientiam«. 67f. Unsälig ... nit waist Augustinus, Confessiones, CC 27, V, Cap. IV,7, S. 60, Z. 68: »Infelix enim homo, qui scit illa omnia, te autem nescit«. 
Zů ainer behaltung der rainikait gehört, das der mensch fliech ursach aller sünd und besunder die unlautterkaÿt. Dann es spricht der zwölffbott: Ir send fliechen die unlütterkä̈t. Es spricht Sant Augustin: Allen sünden mag man in gegenwürtikaÿt widerstan aun allain der unlautterkaÿt von der man fliechen 75 můß. Dann ich han gesechen das die, die ich nit schäczt mÿnder haÿlig dann Sant Ambrosi was, fielen. Die doch, ob sÿ geflochen hetten, bestanden waren. Sag mir, bist du icht haÿliger dann Dauid, weÿser dann Salomon, stercker dann Sampson oder schöner dann Absolon. Die all send gefallen und wären bestanden, werend sÿ geflochen. Und darumb so ist nichtzt bessers dann fliechen.

Des hatt man ain exempel in dem leben Sant Bernhartz. Dann man list, das Sant Bernhart vil junger hett, [fol. $\left.191^{r}\right]$ under den ainer für die andern all sich fliß, gott in allen dingen wolgefallen und beleiben in seiner rainikaÿt. Und wann all ander junger urlaub hettend, außzespacieren, so gieng er allweg ainig oder belib da haim. Die andern brüdern verklagten in und sprachend: Haÿliger vatter 85 Bernharde, der sündert sich auss und macht sich nit gemain unser gesellschaft. Da sprach Sant Bernhart zů im: Warumb flüchst du die gesellen? Der anttwurt: Mein vatter, ich flüch sÿ, wann ich han anderst ze tůnd. Da sprach Sant Bernhart: Was ist, dz du zetůnd hast? Der antwurt: Ich můß zämen ain wildes tier und behalten ain schon junckfrawen und zieren ain altar und ansechen ain totten. Mit 90 den dingen bin ich bekümertt, das ich mit den gesellen nicht wandlen mag. Da sprach Sant Bernhart: Was ist das, dz du sagst? Der junger anttwurt: Das unuernünfftig tier, das ich zämen můß, ist mein [fol. 191 $\left.{ }^{v}\right]$ vichischer leichnam. Hett ich den nit in gůtter hủt und zucht, so übet er sein vichische natur. Die junckfraw, die ich ze behütten han, ist mein sel, mir eingegossen von gott. 95 Darumb, das sÿ nit vermälget werd mit dehainer sünd des leibs oder gaysts. Der altar, den ich ze zieren han, ist mein hercz, auff dem ich mich opffer dem

73 Randnotiz $A$ : apostolus. $\quad$ sünd $B G M N]$ súnden $S$. besunder die unlautterkaÿt $(G M N S)]$ besunder der vnlautterkait $B . \quad \mathbf{7 4}$ Randnotiz A: Augustinus. $\mathbf{7 5}$ aun $(B G M S)]$ dañ $N$. 75f. fliechen můß $(B G M)]$ můß fliehñ $N(S) . \quad 76$ nit schäczt mÿnder $(B G M N)]$ schätzt nicht myndrs $S .77$ Randnotiz A: Ambrosius. Ambrosi $G M(N S)]$ Ambrosium verbessert aus Ambrosius $B$. geflochen hetten, bestanden waren (BGM)] geflochn̄ werdn̄ wären bestandn̄ $N$,

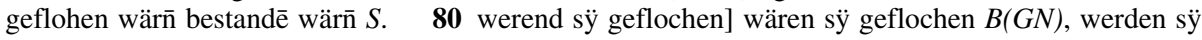
gefloch $M$, ob sy wären geflohē $S$. Und darumb $(B G) M]$ Darv̄̄ $N$, Dar und Randergänzung: vm $S$. 81 Randnotiz A: exempel. leben $G]$ lesen $A B M N S$. Bernhartz $(B N) S]$ bernhart $G M$. Dann $B G(M N)$ ] fehlt $S . \quad \mathbf{8 2}$ all $B G M N]$ alle $S . \quad 83$ gott in allen dingen $(B G M N)]$ jn allen dingen got $S$. beleiben $(B G) M(N)]$ zů beleibē $S . \quad 85$ belib $B$ ] pelayb $G(M)$, belib ab $^{\mathrm{s}} N$, belaib $S$. Die andern brüdern verklagten in $(B G M)]$ Darv $\bar{m} v^{s}$ clagtñ jn die andern brüder $N(S)$. 85f. vatter Bernharde $(B G M)] \operatorname{vatt}^{\mathrm{s}} N(S) . \quad \mathbf{8 6}$ auss $\left.(B G M N)\right]$ auß vns $S . \quad$ macht sich $\left.B M N S\right]$ māch sy $G . \quad$ unser $(B G M)]$ vnß $N$, vnsrs $S . \quad 89 \mathrm{dz}(B G M N)]$ das das $S .91$ bin $(B G) M(S)]$ bin verbessert aus gen $N$. 92 das, dz $(B)]$ das $G M(N) S . \quad 93$ leichnam $(B G) M]$ leib $N S .94$ hůt $(B) G(M S)]$ hutt verbessert aus gutt $N . \quad$ natur $B G]$ natu (?) $M . \quad 95$ eingegossen $B(G M)$ ] ein gozzn̄ $N(S) . \quad 96$ gaysts $(B N S)$ ] gayst $A(M G)$. 96f. Der altar $(B M N) S$ ] Den altar $G .97$ ze zieren han $(B G) M]$ ziern sol $N(S)$. opffer $(B) G M N]$ opffern $S$.

73f. Ir send ... unlütterkaÿt I Cor 6,18. $\quad$ 74-76 Allen sünden ... fliechen můß Ps.-Augustinus, Sermones supposititii, Sermo 293,1, PL 39, Sp. 2301: »contra reliqua vitia, Deo auxiliante, debemus in praesenti resistere; libidinem vero fugiendo superare«. 78f. Sag mir ... Absolon Vgl. ebd., Sermo 293,2 u. 3, PL 39, Sp. 2302 (David, Salomon). 
lebendigen gott und Jhesu Cristo, der sich selbs umb meinen willen geoppffert hatt gott dem vatter auff dem altar des crücz. Der todt, den ich an sechen můß, 100 ist mein töttlichs leben. Wann ich waiß nit, wenn, wa und wie ich sterben wird. Da sprach Sant Bernhart: Mein sun, tů hin für alz du bis her getan hast, so wirst du sälig. Auß dem erscheint, dz der, der begert rainlich zeleben, fliechen můß ursach der sünden.

Zů dem andern lert uns der haÿlig gaist Loicam. Die selbig kunst lert erken${ }_{105}$ nen das war von dem $\left[f o l .192^{r}\right]$ falschen und straffen. Also der haÿlig gaÿst, wann er den menschen pringt zů lautterkaÿt der gewissen, so lertt er in erkennen das war von dem falschen und streitten wider das flaÿsch, wider die welt und den bösen gaist.

Dann zům ersten hept der leib für leÿplich wollust und spricht, $\mathrm{dz}$ gesprochen 110 ist Ecclesiastici: Ich han gelobt die fröd der menschen. Was ist bessers under dem hÿmel dann essen und trincken, wol leben und wollust haben. Aber der haÿlig gaÿst lertt sein schůler anttwurtten, das da spricht der zwölffpott: Die in lust des leibs send, mügent Cristo nit wol gefallen. Der leib begert wider den gaist und der gaist wider den leib. Es spricht auch Aristotiles: Wollust ist wider 115 wollust, alz ob er spräch: wollust des leibs ist wider wollust des gaists. Wann nun der gaist ist ainer hÿmlischen natur und der leib ainer ÿrdischen, darumb so sol man dem gaist leben.

Zů dem andern, so hebt die welt [fol. $\left.192^{v}\right]$ für reichtung und er der welt und spricht: Gott hatt dem herren geben den himel, aber das ertrich hatt er geben den 120 sünen der menschen. Sälig ist der, der genůg da haim hatt, der aber nichtz hatt, ist nichtz wert. Wider das so lert der haÿlig gaÿst anttwurtten, das geschriben ist Johannis: Ir send nit lieb haben die welt noch die ding, die in der welt sind. Der weis hett gold silber und küncklich ere und allen wollust und sprach doch: Ich

98 Jhesu Cristo $B(G N S)$ ] iesus $\overline{x p m} M . \quad 99$ Der todt $B(M N S)$ ] Den tod $G . \quad 100$ wenn, wa und wie $(B G M N)]$ wenn - wie odrs wa $S$. wird $B G M]$ můß $N(S) .101$ hin für $(B) G M N]$ für an $S$. getan hast $(B G) M(S)$ ] hast getan $N . \mathbf{1 0 2}$ der, der $(B G M N)]$ der der da $S$. rainlich $B M(S)$ ] Raynnicklich $G(N)$. můß $N]$ müß $(B) G M$, sol vnd můß $S .104$ Randnotiz $A$ : de loica. andern $(B G) M]$ andern mal $N(S)$. lert uns $(B G M)]$ so lernt vns $N$, so lert vns $S$. kunst lert $(B G) M]$ kunst lernt $N(S)$. 105 Also $B M N S$ ] also das $G . \quad 106$ lerrt $(B G M S)]$ lernt $N . \quad 107$ flaÿsch $(B G N S)]$ falsch $M$. 107f. und den $(B G M)]$ vñ wider $N(S) .109$ Dann $(B) G(M N)]$ fehlt $S$. hept $(B G M)]$ so hept $N(S)$. gesprochen $B G M]$ geschribn̄ $N(S) . \quad 110$ Randnotiz A: ecclesiastici. 110f. bessers under dem hÿmel $(B G) M]$ pössers $N(S)$. 112 lertt $(B G M)]$ lernt $N(S)$. da spricht der zwölffpott $(B G M N)$ ] der zwelfpot spricht $S .113$ Cristo $B G(M N)]$ got $S .114$ Randnotiz, A: Aristotiles. 121 Wider das so lert der haÿlig gaÿst $(B G M)] \mathrm{Abe}^{\mathrm{s}}$ der hailig gaist lernt $N, \mathrm{Abr}^{\mathrm{s}}$ der heilig geist lert $S$. 122 Randnotiz $A$ : Johannis. in der welt $(B) N S]$ yn dÿser welt $G(M)$. 123 Randnotiz A: Salomon. hett $B(G) M(N)]$ hat $S$.

110f. Ich han ... wollust haben Ecl (Ecclesiastes!) 8,15. 112f. Die in lust ... wol gefallen Vgl. Gal 5,16. 113f. Der leib ... wider den leib Gal 5,17. 114f. Wollust ... wollust des gaists Vgl. Augustinus, Sermo 284,4, PL 38, Sp. 1291: »Erat delectatio contra delectationem«; zum Gegensatz >delectatio corporalis<vs. >delectatio spiritualis<vgl. z. B. Aelred v. Rievaulx, Sermones, CCM 2A, Sermo 37 (In natali Sancti Benedicti), S. 300-305, Thomas v. Aquin, In quattuor libros Sententiarum, hg. von R. Busa, Stuttgart-Bad Cannstatt 1980, IV, ds 49, qu 3, ar 4a, rc 2, u. ar 5a, ag 3, S. 693. 119f. hatt dem ... der menschen Ps $(L X X)$ 113,24. 122 Ir send ... welt sind I Io 2,15. 123-126 Ich han ... gaistz Ecl 1,14. 
han gesechen alle ding, die under der sunnen send und gehandelt werdent, und die send nichtzit anderst dann ain üppikaÿt der üppikaÿt und ain peinigung des 125 gaistz.

Man list, das ain ritter sach ain aller schönste frawen, ab der schön er wun-

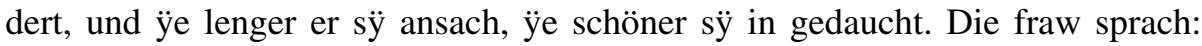
Wie gefall ich dir? Er anttwurt: $\mathrm{O}$ du allerschönste der frawen, ich han dein geleich nie gesechen. Die fraw keret sich von im und sprach: Sich mich hinden, 130 wie $\left[f o l .193^{r}\right]$ ich dir gefall. Da sach er ain ofen prinnen mit schwebel und bech und über all maß übel schmecken. Da sprach der ritter: $\mathrm{O}$ wie ain groß wunder ist das, daz du fornan die aller schönest bist under den weiben und hinden ain prinnender ofen. Was bist du? Die fraw anttwurt: Ich bin die welt, die iren liebhabern gar lieblich und ir spiegel ist, aber das end ist der tod. Alz das dann 135 wol betrachtet Sant Bernhart da er sprach: O du unraine welt, warumb haltest du die menschen also, und du doch zergenklich und in tod fürend bist, was tätest, soltest du ewenklich stan? Es spricht Gregorius: Die welt gronet in vil menschen herczen, wie wol sÿ doch in ir selbs dorret. O liebhaber der welt, veind des crücz Cristi, wie bald hand ir gelassen, das ir spat an gefangen hand. Spat hand ir ${ }_{140}$ gebeichtiget und ÿecz bald send ir vermailgot worden mit sünden. Jhesum hand ir fräuenlich aussge[fol. $193^{v}$ ]triben, den ir mit grosser forcht in ewer herberg genommen hand. Darumb in der engstlichesten not wirt zů eüch gesprochen: Furwar sag ich eüch, ich waiß euch nit.

Zů dem dritten hept der böß gaist für die gab, die der mensch enpfangen hatt, ${ }_{145}$ und spricht: Du bist edel, jung, reich und schön, im alter so machst du wol rüen und gott leben. Aber der haÿlig gaist lert sein schůler anttwurtten: Gang hinder

124 send und gehandelt $(B G M)]$ gehandelt $N$, gesehen $S$. 124f. und die send $(B G M)]$ vn sind $N(S) .125$ peinigung $(B G S)]$ peiniung $M$, peinūg $N .127$ Randnotiz $A$ : exempel. frawen $(B G M N)]$ fehlt $S . \quad$ 127f. schön er wundert $(B G) M S$ ] schein erwūdert er sich $N . \quad 128$ sÿ ansach $B(G) M(S)$ ] sich an sach $N$. gedaucht $B G M(N)]$ daucht $S .130$ hinden $(B G) M(N)]$ hindē an $S$. 131 und bech $(B G M)]$ vñ mit pech $N(S) . \quad 133$ ist das $B(G) M]$ daz ist $N(S) . \quad 136$ Randnotiz $A$ : Bernhart. betrachtet $B(G) M N$ ] betracht $S . \quad$ haltest du $(B G) M N$ ] behaltest $S . \quad 137$ fürend $G(M)$ ] füren $B N S . \quad 138$ ewenklich] ewigclich $B(M N)$, ewigklichen $G(S)$. Randnotiz A: Gregorius. 140 gelassen $B G M$ ] gelassen verbessert aus gelesen $N$, v'lassen $S . \quad 141$ gebeichtiget $(B G) M$ ] gebeicht $N(S) . \quad 143$ engstlichesten $B(G) M]$ ängstlichñ $N(S) . \quad 144$ waiß euch $(B) G(M N)]$ waiß ewr $S .145$ Randnotiz $A: 3.146$ rüen $M S]$ rüwen $(B G)$, růen $N .147$ leben $G M(N)]$ loben $B$, dienen $S . \quad$ lert sein $B G M$ ] lernt dy $N$, lernt sein $S$.

127-135 Man list ... der tod Vgl. F. C. Tubach, Index exemplorum, Helsinki 1969, Nr. 5390; W. STAMMLER, Frau Welt, Freiburg/Schweiz 1959, S. 46f. mit Anm. 141f. $136-138$ O du ... ewenklich stan? Vgl. Augustinus, Sermones de scripturis, Sermo CV (a), Cap. VI, PL 38, Sp. 622: "Quid strepis, o munde immunde? [...] Tenere vis periens: quid faceres si maneres?«; Quodvultdeus, Opera tributa, CC 60, Sermo de symbolo III, I,20, S. 350, Z. 65f.: »O munde immunde, teneris periens; quid faceres si maneres?«. 138f. Die welt ... dorret Gregor d. Gr., Homiliae in Evangelia, Homilia 28,3, PL 76, Sp. $1212 \mathrm{D}$ : »et tamen cum in seipso floreret, jam in eorum cordibus mundus aruerat«. 144 Furwar ... euch nit Mt 25,12. 146f. Du bist ... gott leben Vgl. Ps.-Augustinus, Sermones supposititii, Sermo 293,4, PL 39, Sp. 2302. 147f. Gang ... gotz sind Mc 8,33. 
sich, tüffel, du verstast nit die ding, die gotz sind. Von der jugent spricht der zwelffbot: Wann sÿ sprechend frid und sicherhait, so kompt gächlingen der tod.

150 Von der reichtung spricht der prophet: Wann der reich entschlaufft, so nimpt er nit alle ding mit im. Auch spricht der propheet: Sy länd den frömden ir reichtum. Ÿe grösser nun send die gauben gotz, sÿ seÿend natürlich oder gaÿstlich, ÿe grösser gehört darumb übung der danckpärkaÿt.

Zů dem dritten so lert der haÿlig gaist Rethorick. Die selbig kunst lert klůg${ }_{155}$ lich reden latein [fol. $194^{r}$ ] und brieff schreiben, dar inn sich ainer gegen dem andern nidert und diemütiget. Also der haÿlig gaist, wann er uns macht gott rainiklichen dienen und den leib, welt und den bösen gaist verschmechen, so macht er dann, das wir uns in ainem verlaugen aigens willes gott diemütiklich underwerffen und sprechen mit dem propheten: Die ains diemütigen gaistz wirt 160 gott behalten tůn, den diemütigen geit gott genad, die diemütigen erhöcht gott. Und darumb so lernent von Cristo diemütikait. Dann ir mügent so vast nicht gediemütiget werden, Cristus seÿ noch diemütiger gewesen.

Spricht Jeronimus: Es ist beser ein gan in den himel mit dem diemütigen Cristo, dann gan in die hell mit dem hoffertigen tüffel. Es spricht auch Sant 165 Benedict in seiner regel: Wilt du gediemütiget werden, so solt du dich in deinem herczen, an deinem [fol. $\left.194^{v}\right]$ leichnam und an deinen wercken diemütigen erzaigen. Wilt du diemütig werden, so solt du vernünfftiklich wenig reden und schweigen, bis man dich frag. Wilt du diemütig sein, so solt du dich in allen dingen berait und gehorsam erzaigen und beweisen und dich allweg ain unnü-

148 nit die ding $B G M(N)]$ die ding nit $S . \quad$ jugent $(B) G M(S)]$ jungk $N . \quad 149$ Randnotiz, A: Apostolus. gächlingen $(G M) N]$ gächlinger $B$, gähling $S . \quad 150$ Randnotiz $A$ : propheta. der reich $B G M S$ ] der der reich $N$ (bei Seitenwechsel). 151 Randnotiz A: propheta. frömden $G(M N) S$ ] frainden $B .152$ gauben $(B G M N)]$ gab $S .153$ gehört darumb übung der danckpärkaÿt $(B G M N)]$ v̈bung der danckperkeit gehört darvmb $S . \quad 154$ Randnotiz A: $3 . \quad$ Randnotiz A: Rethoricam. Zů dem $(B G M N)]$ Züm $S$. so lert BGMS] so (nachgetragen) lernt $N$. gaist $(B G) M N(S)]$ fehlt $A$. Rethorick $G(M N S)$ ] Rethoricam $B$. kunst lert $(B) G M S$ ] chunst lernt $N$. $156 \operatorname{gott}(B G M N)]$ fehlt $S .157$ rainiklichen dienen $(B G) M]$ rainlich lebn̄ $N(S)$. welt $(B) G N]$ die welt $M S$. den bösen $B(G) M(S)$ ] pösen $N$. 158 verlaugen $(G) M]$ verlaugnen $B(S)$, verlängen $N$. 159 Randnotiz $A$ : propheta. gaistz $(G) M]$ gaistes sind $B$, gemütes sind $N$, gemutes $S$. 160 behalten tůn $(B G M)]$ behaltn̄ $N S . \quad \operatorname{den} B G M] \operatorname{dē} N, \operatorname{dem} S .163$ Randnotiz, A: Jeronimus. Spricht Jeronimus $B(G)$ ] Es spricht jeronim ${ }^{9} M(N)$,.S.. Jeroni ${ }^{9}$ spricht $S$. 163f. ein gan in den himel mit dem diemütigen Cristo $(B)]$ ein gēn jn den hymel mit den ... $G$, eingang in den himel mit dem ... $M$, ein gen jn himel mit dē ... $N$, ein gen mit dē diemüttigē $\overline{x p o}$ in den himel $S . \quad 164$ gan $B(G) N(S)$ ] fehlt $M . \quad 165$ Randnotiz A: Benedictus. 166 leichnam $(B) G M]$ leib $N S . \quad$ und an deinen wercken diemütigen $(B G M)]$ vn̄ jn deinē werckn̄ diemüticlich $N$, Jn deinē werckē diemüttigklich $S .169$ dich $B G M N]$ auch $S$.

149 Wann sÿ ... der tod Vgl. I Th 5,3. 150f. Wann der ... mit im Ps (LXX) 48,17f., Iob 27,19. 151 Sy länd ... reichtum $P_{s}(L X X) 48,11$ 159f. Die ains ... behalten tůn $P s(L X X) 33,19$. 160 den diemütigen ... genad $I a c$ 4,6, I Pt 5,5. die diemütigen erhöcht gott $E z, 21,26, L c$ 1,52. 163f. Es ist beser ... hoffertigen tüffel Vgl. Augustinus, Expositiones, CSEL 84, Expositio ad Galatas, 24,6, S. 86, Z. 23 - S. 87, Z. 1: »Restat ergo, ut qui mediatore superbo diabolo superbiam persuadente deiectus est, mediatore humili Christo humilitatem persuadente erigatur «. 167 Wilt du ... erzaigen Vgl. Benedicti Regula, CSEL 75, VII,62f., S. 50f. $\quad$ 167f. Wilt du ... dich frag Vgl. Benedicti Regula, CSEL 75, VII,56, S. 50. 168f. Wilt du ... und beweisen Vgl. ebd., VII,34, S. 45f. 169f. dich allweg ... scheczen Vgl. ebd., VII,49, S. 48. 
czen diener scheczen. Wilt du diemütig sein, so solt du nit lieb haben dein aigen 170 willen und in allen widerwärtigen dingen gedultig sein. Dann wa diemütikait ist, da ist gedultikaÿt. Und wa gedult, da ist die lieb. Dann die lieb ist gedultig.

Zům vierden so lert der haylig gaist Musick. Das ist wol singen in gaÿstlicher fröd. Es spricht Sant Augustin: Alz die natürlich stimm nit ist on leiplichen gaist, also ist auch die gaistlich stimm nit on den haÿligen gaist. Und darumb 175 spricht der prophet: Singent dem herren ain nü gesang, dan er hatt wunderbere ding getan. Nun sechen wir das in ainem ÿeglichen maisterlichen [fol. $195^{r}$ ] gesang dreÿ stimm send, die under, die mittel und die höchst. Also sol auch in dem gaistlichen gesang sein dreÿ stimm, das ist die stimm des herczen, des munds und des wercks. Der mund halt die under stimm. Dann vil menschen 180 lobend gott mit dem mund on das hercz. Es spricht da von Ÿsaÿas: Das volk eret mich mit den leffsen, ir hercz ist aber verr von mir. Die werck haltend die mittel stimm, das hercz die aller höchsten. Dann wär andacht des herczen nit da beÿ, so wer das gebet des munds und würcken des leibs wenig nücz.

Aber das gesang des herczen, munds und wercks macht dem herren lust und 185 verjächt den bösen gaist, als geschriben ist am ersten bůch der künig am xiii capittel: Wann der bös gaist Saul den künig peiniget, so sang Dauid auff der härpffen, und dann so verließ der bös gaist künig Saul. Also, wann wir gott loben, so mach wir auch den bösen gaist [fol. $\left.195^{v}\right]$ flüchtig von uns. Dann es spricht Sant Jacob: Widerständ mit andächtigem gebet dem bösen gaist, so wirt ${ }_{190}$ er von euch fliechen.

171 gedultig sein $B G M$ ] dultig sein $N$, gedultig $S .172$ wa gedult] wa gedúlltikait ist $B(N S)$, wo gedult ist $G M$. da ist die lieb $B N S$ ] da ist lieb $G M$. gedultig $(B) G M(S)$ ] dultig $N$. 173 Randnotiz A: 4. Randnotiz A: Musick. lert $B G M S]$ lernt $N$. Musick $(M N S)$ ] Musicam $B$, müsick $G .174$ Randnotiz $A$ : Augustinus. fröd $(B G) M(N)]$ fehlt $S . \quad$ on $B(G M)]$ an ain $N(S)$. 175 haÿligen $(B G N)]$ gaistlichen $M$, heiligē heilign̄ (bei Zeilenwechsel) S. 176 Randnotiz A: Dauid. prophet $(B G N)]$ pprohet $M$, heilig prophet $S .177$ in $(B G) M]$ nachgetragen $N$, fehlt $S$. 178 und $(B G M N)$ ] fehlt $S . \quad \operatorname{sol}(B) G M N$ ] fehlt $S .179$ gesang $G M N(S)]$ fehlt $B . \quad \operatorname{sein} B G M N$ ] sind $S . \quad 180$ mund $(B G) M N$ ] fehlt $S . \quad$ under $(G S)]$ vnndern $B(N)$, ander $M .181$ Randnotiz $A$ : ysayas. da von $B G M]$ fehlt $N S . \quad 182$ mit den leffsen $(B G M)]$ mit dē mūd $N(S) . \quad 182$ ir hercz ist aber $(B G) M(S)] \mathrm{ab}^{\mathrm{s}}$ daz ir hercz ist $\left.N . \quad \operatorname{mittel}(G) M(N)\right]$ mittlen $B$, myttr'n $S . \quad 184$ würcken des leibs $(B G M)$ ] des wes cks $N(S) .185$ munds und wercks $(B) G(M)$ ] dez mūdes vñ des werckes $N(S)$. herren $B G(M)]$ h h $n$, hören $S . \quad \mathbf{1 8 6}$ Randnotiz $A$ : Regum. verjächt $(B G M N)]$ v'treibt $S . \quad$ am $B G M]$ an dē $N$, an den $S . \quad$ xiii $G M N$ ] dreÿtzechenden $B$, xiiij $S . \quad 187$ Saul den künig $B(G M N)$ ] den kunig saul $S . \quad 188$ und dann so $(G M)$ ] vnnd dann $B$, so $N S .189$ mach $G M N S$ ] machen $B$. wir auch $B G M$ ] wir $N S . \quad$ Dann $B(G M N)$ ] wann $S .190$ Randnotiz A: Jacobus. Widerständ $(B G M N)]$ widr $^{s}$ stee $S . \quad$ andächtigem $\left.B G M(S)\right]$ andächtigen $N$.

170f. Wilt du ... gedultig sein Vgl. ebd., VII,35, 38 u. 42, S. 46f. 174f. Alz die ... haÿligen gaist Vgl. Augustinus, Enarrationes in Psalmos, CC 38, Ps. 5, § 2, Z. 5f., S. 19f.: »quandoquidem uox corporalis auditur, spiritalis autem intellegitur «.

176f. Singent ... getan $P s$ (LXX) 97,1. 181f. Das volk ... von mir Is 29,13. 187f. Wann der ... künig Saul $I S m$ 16,15 u. 23.

190f. Widerständ ... fliechen Iac 4,7. 
Zům fünfften so lert uns der haÿlig gaist Arismetrick. Dann er lert uns zelen alle gůt tät gotz uns geschechen, alz die schöpffung und widerschöpffung, erlösung, gebung der sacrament und verhayssung seins reichs.

195 Wann wir nun das wöl gezellen, so gehört darzů ain sagen der danckpärkaÿt. Es spricht Sant Augustin: Wie wol gott allmächtig ist, so hatt er doch uns nit me mügen tůn dann er getan hatt. Wie wol er ist die ewig weisshait, so hatt er doch nit me gewist und ze tůn. Wie wol er ist der aller reichest, so hatt er doch nit me gehept ze tůn. Darumb, es seÿ dann, das wir umb die enpfangen gůt tüen übung 200 der danckperkait, so werdent uns alle ding, uns gegeben zům haÿl, verkert zům tod. Dann es spricht Sant Bernhart: Undanckparkait hatt gehasset mein sel, dann sy drücknet den brunnen göttlicher milltikait.

Zům sechsten [fol. $196^{r}$ ] lert uns der haÿlig gaist Geometrÿ. Das ist, er lert uns messen das land der lebendigen und nit der totten. Dann es spricht Sant ${ }_{205}$ Augustin: Wann du messen wirst das land der sterbenden, so wirst du von dem ertrich gemessen. Dann am end so wirst du von dem ganczen ertrich nichtzit haben dann im grab die lengin sÿben schůch. Und darumb sprach ain natürlich maister von dem grossen Allexander: Der was gester nit genügig der ganczen welt, heẅt last er sich genügen im ertrich der weit sÿben schůch. Und darumb so 210 süll wir messen das ertrich der lebendigen, das all lerer der welt nit wissend ze messen.

192 Randnotiz A: 5. Randnotiz A: Arismetrick. Z Zům $G M(S)]$ Zủ $\operatorname{dem} B(N)$. fünfften $(B G M)]$ fünftn̄ mal $N S$. So lert uns $(G M)]$ lert vnns $B$, so lernt $N$, so lert $S$. Arismetrick $(G) M(N S)]$ Arÿsmetricam $B . \quad$ er lert $B G M S$ ] er lernt $N$. 193 gůttät $B(S)$ ] gůtthaÿt $A(G M N)$. uns geschechen $(B N S)]$ vnnd geschehen $G(M)$ widerschöpffung $(B) G(M N)]$ widrsschöpffen $S$. 194 der sacrament und $(B M)$ ] dez Sacramecz vnd $G$, der sac̃mēt $N(S)$. 195 nun das $(B G) M(N)$ ] das nū $S$. sagen der danckpärkaÿt $(G M)$ ] der danckperkait $B$, danckperkait sagen $N(S)$. 196 Randnotiz A: Augustinus. doch uns $(B) M]$ vns doch $G N S .197$ getan hatt $(B) M(N S)]$ vns gethan hat $G$. 198 gewist und ze tůn $(G)]$ gew ÿßt ze thǔn $B$, gehebt ze tun $M$, gewist vns ze tun $N(S)$. reichest $(B G) N S$ ] rechtest $M$. hatt $(B G M S)]$ fehlt $N .199$ ze tůn $(B G M)]$ vns ze tun $N(S)$. gůt $(B G M) N]$ gůttat $S .200$ uns gegeben $M$ (in A Vorsilbe ge nachgetragen)] gegeben $B G(N)$, gebē S. 201 Randnotiz A: Bernhardus. dann $B G(M)]$ wan̄ $N(S) .202$ göttlicher milltikait $(B G M N)]$ der parmhertzigkeit vnd gotlichrs myltigkeit $S . \quad 203$ Randnotiz A: 6. Randnotiz A: Geometrÿ. Zùm $(B) G M]$ Zw dē $N(S)$. lert $B G M S$ ] lernt $N$. Geometrÿ $(M)]$ Geometriam $B$, Geometrey $G(N S)$. 203f. er lert uns $(B G M)$ ] fehlt $N S .204$ Dann $B G(M N)]$ Wann $S .205$ Randnotiz A: Augustinus. 206 am end so] am ennd do $B$, ayn end so $G(M)$, an end so $N$, on endt so $S .207$ lengin $B M]$ leng yn $G$, lenge $N$, leng $S$. darumb $B(M N S)]$ darumb so $G$. 207f. Randnotiz. A: phÿlosophus. 209 im ertrich der weit sÿben schůch $(B G M)] \mathrm{d}^{\mathrm{s}}$ lenge siben schůch jm ertrich $N(S)$. so $\left.B G M\right]$ fehlt NS. 210 messen GMNS] fehlt B.

201 Undanckparkait ... mein sel Ps.(?)-Bernhard v. Clairvaux, Sermo II pro dominica VI post Pentecosten: De septem misericordiis, 1, PL 183, Sp. 339 C: »sed ingratitudinem prorsus odit anima mea«. 208f. Der was ... sÿben schůch Vgl. Gesta Romanorum, hg. von H. Oesterley, Berlin 1872, Nr. 31, S. 329, Z. 25f.: »Heri non sufficiebat Alexandro totus mundus, hodie sufficiunt ei tres vel quatuor ulne panni«; ähnlich Gesta Romanorum, hg. von W. Dick, Erlangen/Leipzig 1890, Nr. 66, S. 44 . 
Und das süllen wir tůn mit den dreÿen massen, mit den alles das gemessen wirt, das da ist in himel und in ertrich, das ist mit der gesicht, gehörd und gedencken des herczen. Dann es spricht Ÿsaias: Das aug hatt nit gesechen noch das or gehört, noch in des menschen herczen ist nie kommen die ding die gott 215 [fol. $196^{\circ}$ ] berait hatt dienen, die in lieb hand.

Es spricht der zwölffbott: Von des wegen so büg ich meine knie gegen dem vatter meins herrn Jhesu Cristi, das ir mügent begreiffen mit allen haÿligen, was seÿ die höche götlicher maiestät, die dieffin der ungeschöpfften und ewigen weishait, die weittin seiner einwonung und die lengin der ewikaÿt. Und wann 220 die ding wol gemerckt werden, so spricht der schůler: Ich gelaub zesechen gůtte ding in dem ertrich der lebendigen.

Zů dem sybenden lert uns der haÿlig gaist Astronomÿ. Das ist schawen den lauff der planeten und sterrn. Das ist, er lert uns mercken das leben der haÿligen vätter. Es ist geschriben in dem bůch der geschöpfft: Sich den himel und zel die 225 sterrn ob du mügest, als ob er spräch: merck die himlischen menschen und die haÿligen vätter, in welcher weis und wie sÿ gott gedient hand, und folg dem nach. Es spricht Judith: Send ingedenck wie behalten send worden unser vätter. Und alz du vindest das ain sterrn von dem andern underschaid hatt in der klarhait, also hatt das leben der [fol. $\left.197^{\prime}\right]$ haÿligen underschaid von unserm 230 arbatsäligen leben. Es spricht Jeronimus: Wir sollen sůchen exempel der gůtten darumb, das wir in tugenden zů nemen.

212 das süllen wir $B(G) M$ ] süllen daz $N(S)$. mit den alles $B G M]$ mit dē alles $N$, mit dem alles $S$. 213 mit der gesicht $G M(N) S$ ] mit gesicht $B .214$ Randnotiz. $A$ : ÿsaias. hatt $B(G M N)]$ het $S$. 216 berait hatt dienen $(\mathrm{BM})]$ peraitt hat dienen $\operatorname{den} G$, dienē berait hat $N$, berayt hat $\operatorname{den} S$. 217 Randnotiz A: Apostolus. Von des wegen $(G) M S]$ Vmb des wegen $B$, vō des weg ${ }^{\mathrm{s}} N$. meine $(B G) M S$ ] mein $N . \quad$ gegen $B G M$ ] gegē got $N S . \quad 218$ Jhesu $B G(N S)]$ ies $^{9} M . \quad 219$ höche $\left.(G) M\right]$ höchin $B$, höch $N$, hoch $S . \quad$ götlicher $(B) M(N S)$ ] götliche $G .220$ lengin $(B)]$ legin $G M$, lenge $N(S)$. wann $B G(M)]$ wen $N$, wenn $S . \quad 223$ Randnotiz A: $7 . \quad$ Randnotiz A: Ast ${ }^{\circ}$ nomÿ. sybenden $(B G M N)$ ] sibēten mal $S$. lert $B G M S$ ] lernt $N$. Astronomÿ $M$ ] Astronomÿam $B$, Astronomeÿ $G(N S) . \quad 224$ lert $B G M S]$ lernt $N . \quad 225$ Randnotiz A: Genesis. den himel $(B G) M N$ ] die himel $S . \quad 227 \operatorname{dem} B G M]$ dē $N$, den $S .228$ Randnotiz A: Judith. 229 von dem andern underschaid hatt $(B) M(N)]$ vnterschaid hat von dem ander ${ }^{s} n, v^{\prime} t^{s}$ schaidt vō dem andr's hat $S . \quad 230$ haÿligen $(B G M S)$ ] häiligen vätter $N . \quad 231$ Randnotiz A: Jeronimus. Jeronimus $B G M(N)] \cdot \mathrm{S}^{*}$ Jeroni $^{9} S . \quad$ arbatsäligen $\left.(B G M S)\right]$ arbent sälgn̄ $N$.

214-216 Das aug ... lieb hand Is 64,4 (mit Add. in $C \Sigma \Lambda$ ): »oculus non vidit Deus absque te (nec auris audiuit nec in cor hominis ascendit) quae praeparasti expectantibus te $\ll$. 217f. Von des wegen ... Cristi Eph 3,14. 218-220 das ir ... lengin der ewikaÿt Vgl. Eph 3,18; ferner z. B.: Adam Skotus, Sermo 26,IX, PL 198, Sp. 250 D: »Discent sancti, qui bene comprehendent, quae sit latitudo, longitudo, sublimitas, et profundum (Ephes. III,18). Sublimitas potentiae, profundum sapientiae, latitudo charitatis, longitudo aeternitatis«; ders., Sermo 38,VI, PL 198, Sp. 345 C/D: »comprehendens longitudinem aeternitatis ... latitudinem charitatis ... sublimitatem majestatis ... profundum sapientiae«; vgl. ferner Helinand v. Froidmont, Sermo 8, PL 212, Sp. 547 C: »Sic enim comprehenditur quae sit latitudo dilectionis divinae, longitudo aeternitatis, sublimitas potestatis, profundum sapientiae«; ders., Sermo 10, PL 212, Sp. 569 C: »Propter has quatuor dimensiones signum crucis factum est, attingens a fine usque ad finem fortiter, per longitudinem aeternitatis ... per latitudinem charitatis ... per sublimitatem potentiae ... per profunditatem sapientiae«. 221f. Ich gelaub ... lebendigen $P s(L X X)$ 26,13. 225f. Sich ... mügest Gn 15,5. 228 Send ingedenck ... vätter Vgl. Idt 8,21 (?). 231f. Wir sollen ... zů nemen Gregor d. Gr., Homiliae in Hiezechihelem, CC 142, II, Homilia 5,21, S. 291, Z. 531f: »exempla bonorum saepe quaerimus, ut in moribus proficiamus«. 
Man list, das ain künig hort sagen von ainem aller clůgsten maler. Zů dem schickt er dz er zů im käm. Alz er nun kam, sprach der künig zů im: Mach mir 235 das aller schönst bild, das in der welt seÿ, dann du wirst gehaÿssen der aller clůgest maister des malens. Der maler anttwurt: Herr ain grosse sach begerst, dann es ist kain maister so gủt man vind sein geleich. Doch so berieff für mich alle junckfrawen und jüngling deins reichs. Da das nun geschach, da marckt der maler antlüt, augen, hend, füss und alle gelider aller der, die für in berüfft waren.

${ }_{240}$ Und welcher das schöner antlüt, augen, hend, füss hett, nach dem malet er und machet also dz aller schönest bild. Also welcher mensch begert geleich werden Cristo, der sech an die bildung der haÿligen und gůtten menschen und merck an aim rainikait, an dem andern diemüti[fol. $197^{v}$ ]kä̈t, an dem drÿtten gedultikaÿt. Und wann er also sicht die exempel der gůtten, so wirt er auch gebessert.

245 Das wir nun also vom haÿligen gaist lernen, so legt er uns für drü grosse bücher. Dann den anfachenden menschen legt er für zů ainem bůch das gancz ertrich, den würckenden das firmament, den volkommen menschen den fürin himel.

Zů dem ersten so legt er den anfachenden für das ertrich, das sÿ lernend am ersten erkennen ir aigen gebrechen. Dan als das ertrich schwecher ist allen andern elementen, also sol der anfachend mensch mercken sein schwachaÿt, böse werck, die er verpracht hatt, und gůtte ding, die er underwegen gelassen hatt, und sich des schämen. Es spricht der zwölffbott: Was nucz hand ir gehept in den dingen, der ir eüch yeczund schämend? Und also in dem bůch des ertrichs 25 lernend sÿ erkennen ir aigen gebrechen und darnach gediemütiget werden.

Dann den anfachenden list der haÿlig gaist $\left[f o l .198^{r}\right]$ die letzigen: Mensch du solt gedencken, wann du bist äsch und wirst wider kommen zů äschen. Darumb so leb also auff ertrich das du begerest zů sterben.

233 Randnotiz A: Exempel. 234 sprach $(B) G]$ da sprach $M(N S) . \quad \operatorname{mir} B M N S]$ mich $G$. 236 ain grosse sach begerst $B(M N S)]$ ir pegert eyner grossē sach $G .237$ dann $(G M N S)$ ] Wann $B$. es ist kain maister so gŭt $(B G M)$ ] er ward chain maist ${ }^{\mathrm{s}}$ nie so gut $N$, es ward chain maistr" nye so gụt $S$. $\quad$ vind $B(G) M(S)]$ fund $N . \quad 239$ füss $(B G M)]$ vñ füß $N(S) . \quad 240$ füss $(B G M)]$ vñ füß $N$, vnd füß vnd allew gelider Aller der die für jn gerüft warn̄ vnd welchrs das schönr ${ }^{s}$ antlutz Augen hendt vnd füß (Wiederholung) $S$. malet $B G(N) S]$ maltet $M . \quad 241$ also dz aller schönest bild $(B M N)]$ also daz aller schonst antzlitz vnd pild $G$, fehlt $S . \quad \mathbf{2 4 2}$ gůtten $(B G M)]$ gutte $N(S) .244$ wann $B G(M) S$ ] so $N$. gebessert $(B G M N)]$ pessert $S .245$ Das wir $B(N) S]$ Da wir $G$, dar wir $M$. vom haÿligen $(B N)]$ vō heyligem $G$, von hailigem $M$, von dē heiligē $S .246$ Randnotiz A: incipientipus. Dann $B(G M N)]$ fehlt $S . \quad$ menschen $(B N S)$ ] fehlt GM. 247 Randnotiz A: proficientibus. Randnotiz A: perfectis. 249 Randnotiz $A: 1 . \quad$ den anfachenden für $B G M]$ für den anfachendē $N(S) . \quad 250$ gebrechen $(B G M N)]$ prechē $S . \quad$ 250f. allen andern $(B M) N(S)]$ andern allen $G$. 252 verpracht $B(G) M(S)]$ volpracht $N$. 252f. gelassen hatt $(B G M)$ ] hat gelassen (ge nachgetragen) $N$, lassen hat $S$. 253 Randnotiz $A$ : Apostolus. 254 yeczund $(B G) M]$ yecz $N(S)$. 255 gebrechen und $(B G M)$ ] gebrechn̄ $N$, prechē $S .256$ der haÿlig gaist $(B G M)]$ er $N S$. letzigen] letzgñ $B$, letzen $G(S)$, leczigen $M$, leczñ $N . \quad 257$ wann $B G M]$ daz $N(S) . \quad$ äsch $B(G M)$ ] achen $N$, aschē $S . \quad$ wider $B M(N S)$ ] fehlt $G . \quad$ kommen $B(G M)$ ] fehlt $N S$.

233-241 Man list ... schönest bild Vgl. Gesta Romanorum, hg. von H. Oesterley, Berlin 1872, Nr. 62, S. 370f.; Gesta Romanorum, hg. von W. Dick, Erlangen/Leipzig 1890, Nr. 155, S. 126f.; weitere Nachweise bei F. C. Tubach, Index exemplorum, Helsinki 1969, Nr. $3864 . \quad$ 253f. Was nucz ... schämend Rm 6,21. 256f. Mensch ... äschen Aschermittwochs-Benediktion nach Gn 3,19, vgl. A. Franz, Die kirchlichen Benediktionen im Mittelalter, Freiburg i. Br. 1909, Bd. 1, S. 464, Anm. 2. 
Wie aber der gaystlich leben söll, lert der haÿlig gaist in der gesicht die ezechiel sach. Der selbig sach die antlüt der vier evangelisten, des ainen in 260 gestalt ains menschen, des andern in gestalt ains leo, des dritten in gestalt ains ochsen, des vierden in gestalt ains adlers. Alz ob der haÿlig gaist spräch: Wölcher in gott zů nemen will, der sol haben ain antlüt des menschen in der gemain, also das er miltsamlich diemütiklich und fridsamlich wandel mit allen menschen. Im dormiter sol er haben ain antlüt des leon also das er keck seÿ im 265 widerstan den begirlichaÿtten und versủchungen. Im refecter sol er haben das antlütt des ochsen, also das er kostlicher und zartter speis nit achte. Im kor oder kirchen sol er haben ain antlüt des adlers, [fol. $\left.198^{v}\right]$ also das er in seinem gemüt und andacht erhöcht werd in gott.

Zư dem andern, so legt der haÿlig gaist den würckenden für zů ainem bưch 270 das firmament, das ist den gestirneten himel, das sy dar an lernen in got. Dann alz das fürmament umb gat die ganczen welt und täglich seinen lauff verbringt, also sol der würckend mensch täglich verpringen seinen lauff.

Den selben list der haÿlig gaist die letzgen des zwölffbotten, der da spricht: Gůtz tůnd süllen wir nit abnemen. Dann Gregorius spricht: Das gegenwirtig ${ }^{275}$ leben ist nit anderst dann ain weg durch den wir faren zům vatterland. Nun wirt der weg nÿmmer verpracht man begreiff dann das end: Und darumb so mag ain gùtter würcker am end sprechen: Den lauff han ich verpracht, den gelauben han ich behalten. Aber laider vil gaistlicher menschen nemant mer ab dann zů.

Wann man list im leben der vätter das ain gủtter brůder gott batt das er im 280 zaigte das leben der gaistlichen. Dem [fol. 199 ${ }^{r}$ ] erschain der engel und sprach: Stand auff und komm mit mir. Der engel fürt in auff ain hochen berg, auff dem

259 leben $B G M(N)$ ] sterben $S . \quad$ gaist $(G) M N(S)]$ fehlt $B . \quad \mathbf{2 6 0}$ Randnotiz A: ezechiel. 262 ochsen, des vierden in gestalt ains $(B G N S)$ ] fehlt $M .264$ miltsamlich $B G M$ ] miltsämlich sey $N$, mytt'samlich sey $S . \quad$ wandel $(B)]$ wandeln $G$, wandlen $M$, fehlt $N S . \quad 265$ Im dormiter $(G M)$ ] Jnn dem Dormitor $B$, jn dormitory $N$, ym slaffhaus $S$. des leon $B G M$ ] ains leo $N$, ains leben $S$. also $(B) G(M) N(S)$ ] also / also $A$. 265f. im widerstan $B(G)]$ im wider stant $M$, ze widssten $N(S)$. 266 den begirlichaÿtten und versůchungen $(B G M)] \mathrm{de}^{\mathrm{s}}$ begirlichē $\mathrm{v}^{\mathrm{s}}$ süchūg $N(S)$. refecter] $\operatorname{Re}-$ uetter $B$, Refector $G(M)$, refeter $N$, reffenter $S$. 267 kostlicher und zartter $(B G M)]$ zarter vin chöstlich $^{\text {s }} N(S)$. $\quad$ kor $\left.M N\right]$ Chor $B(S)$, kör $G$. 267f. oder kirchen $\left.B(G) M\right]$ fehlt $N S . \quad 268$ ain antlüt $(B G M)]$ an antlüt $A$, daz antlicz $N(S)$. in seinem (BGM)] jn (nachgetragen) seinē $N$, sein $S$. 270 Randnotiz $A: 2$. der haÿlig gaist $(B G M)]$ er $N S . \quad 272$ umb gat $(B G N S)]$ vnd gat $M$. verbringt $(B G M)$ ] volpringt $N S$. verpringen $(B G M N)]$ volpringē $S .274$ Randnotiz A: Apostolus. letzgen] leczgen $B M$, letzen $G S$, leczñ $N . \quad 275$ Randnotiz $A$ : Gregorius. $\quad$ Gůtz tůnd ... Gregorius spricht $(B G M)]$ fehlt NS. 278 Randnotiz A: Apostolus. 279 behalten $(G) M(N S)]$ fehlt $B$. 280 Randnotiz A: Exempel. $\quad \operatorname{im}(B G) M(N)]$ in dem $S$. batt $(G M N S)]$ bätt $B$. 280f. im zaigte $(G M N S)]$ zaigte $B . \quad 282$ Randnotiz $A: 1$.

259f. gesicht die ezechiel sach Vgl. Ez 1,10 u. 10,14 sowie die exegetische Tradition (z. B. Hieronymus, Mt-Kommentar, CC 77, Prolog >Plures fuisse`, S. 3f.; zum weiteren Traditionshorizont vgl. LCI I, Sp. 696; RDK VI, Sp. 517-519). 275 Gütz ... abnemen Gal 6,9. 275f. Das gegenwirtig ... vatterland Gregor d. Gr., Homiliae in Evangelia, Homilia 11,1, PL 76, Sp. 1115 A: »In praesenti etenim vita quasi in via sumus, qua ad patriam pergimus «. $\quad$ 278f. Den lauff ... behalten II Tim 4,7. 280ff. Wann man list im leben der vätter ... In den gängigen >Vitas patrum<-Fassungen nicht nachweisbar. 
sach er ain holen baum, in dem bran ain fürr, und vogel sassend auff den esten des baums. Zù den selben vogel sprach ain stimm von hÿmel: Wachent das ir nit 285 fallend in den tod. Da sprach der brůder zům engel: Was ist das? Anttwurt der engel: Der baum betütt die gaistlichen, die da hand den namen und gewand, aber nit das leben. Dann in in brint das fürr der begirlichait und nit das fürr des haÿligen gaistz. Darumb wirt zů in gesprochen: Wachent, wann ir wissend nit, wann der herr komen wirt.

290 Zưm andern fürt er in auff ain veld lustlich von blůmen, feicht von taw und regen. Da sach er menschen siczen in grünendem hain, wollust haben, die weder das taw noch regen berürt. Da fragt der brůder: Wer send die? Antwurt der engel: Sy send die, die wedar durch predig noch durch einsprechen [fol. 199 ${ }^{v}$ ] noch durch exempel ander menschen nit fücht send worden durch die andacht, 295 die da hand ain drucken dürr sel. Die sprechend mit dem psalmisten: Mein sel ist dürr, geleich als das ertrich on wasser.

Zů dem dritten fürt er in auff ain veld, da sach er menschen, die warend an ainer seÿtten warm und an der andern kalt. Da sprach der engel: Das send die gaistlichen, die gehorsam send in dem, das in wolgefelt, und nit in dem, das in 300 missfelt. Es spricht Sant Bernhart: Ain warer gehorsamer der beẅt sein oren der gehörd, sein zungen der stÿmm, sein hend dem werck, sein füss dem gang und verlengert es nit.

Zů dem vierden fưrt er in auff ain veld, da sach er menschen beklaitt mit schwarczen kappen, blaich under anttlüt als das wachs. Da sprach der engel: Die 305 send murmler, erabschneider, die in allen dingen ain mißfallen hand, die gott hessig send. Dann in dem das sÿ ander menschen urtailend, so verdampnend si sich [fol. $\left.200^{r}\right]$ selbs.

Zům fünfften zaigt er im ain hochen türen, auff dem sassend weiß tauben, von den fielen die feder. Alz sÿ nun blutt wurden, da fielen sÿ und warden verzert

283 bran $(B G M)]$ päm $N$, paum $S .284$ baums $(B G M N)]$ fehlt $S .285$ zům $(B G M)]$ zw dē $N(S)$. 288 Darumb $B G(M)] \mathrm{da}^{\mathrm{s}}$ vm so $N(S) . \quad 290$ Randnotiz $A: 2 . \quad$ Zům $\left.(B G M S)\right] \mathrm{Zw} N$. lustlich von $(B)]$ lüstlich mit $G(M S)$, lusticlich mit $N .291$ grünendem $G M]$ grönenden $B$, grönendn̄ $N$, grönetē $S$. hain (?)] kain $A(B) G M$, dehain $N$, chain $S . \quad$ die $B G M]$ vn $N(S) . \quad 292$ das taw noch regen berürt $(B G M)$ ] regen noch taw berüeret sy $N(S)$. fragt $B G M]$ vos schat $N$, vorschet $S$. Antwurt $B(G) M]$ da antwurt $N(S)$. 293 einsprechen $B G]$ ein sprechen $M(N)$, ein sprechē des heiligē geistes S. 294 durch exempel $B(G) M]$ exempl $N(S) . \quad$ nit $B M]$ nie $G N(S) .295$ Randnotiz, $A$ : dauid. die da $B G M]$ die $N S . \quad 296$ als das $B(G) M]$ dem NS. 297 Randnotiz A: 3. 298 Randnotiz, A: nota. 299 wolgefelt $(B G M)]$ gefelt $N(S) . \quad 300$ Randnotiz A: Bernhardus. $\quad$ spricht $(B G M S)]$ sprich $N$. 300f. der gehörd $B M(S)]$ dem gehord $G$, dē hörūg $N$. 301 gang $B G M N]$ gen $S$. 302 nit $B N(S)]$ ist $G M . \quad 303$ Randnotiz $A: 4 . \quad Z \mathrm{Zu} \operatorname{dem}(B G M)] \mathrm{Z} \overline{\mathrm{w}} N(S)$. 304 under anttlüt $(G M N)]$ vnnderm antlütz $B$, vntr ${ }^{\mathrm{s}}$ dē antlutz $S$. wachs $\left.B G M N\right]$ war $S$. $\mathbf{3 0 5}$ murmler $\left.(B G M) N\right]$ mürbler $S . \quad$ ain $B(G) N S]$ fehlt $M . \quad 309$ nun blutt wurden $(G) M(N)]$ noch (verbessert aus nun?) blutt wirden (verbessert aus warden?) $A$, noch plūtt wären $B$, nu ploß wurden $S$.

288f. Wachent ... komen wirt Mt 24,42 (Mc 13,35). 295f. Mein sel ... wasser Ps (LXX) 142,6 . 300f. Ain warer ... dem gang Bernhard v. Clairvaux, Sermones, III, hg. von J. Leclercq/H. Rochais, Rom 1970, De diversis, Sermo 41: De via oboedientiae, 7, S. 249, Z. 8-10: »Fidelis oboediens ... parat oculos visui, aures auditui, linguam voci, manus operi, itineri pedes«. 
von wurmen. Da sprach der engel: Das send die, die im gaist an fachend und im 310 flaisch endent. Wider die spricht der zwölffbot: Ir send sechen, das ir das, das ir im gaist anfachend, nit im flaisch erendent.

Züm sechsten zaigt der engel im ain hauss, darinn was cristall, der hett in im brinnendes fürr. Da hort der brůder ain stimm: Das ist ain einwonung der haÿligen drÿualtikaÿt. Da sprach der engel: Das send die gùtten gaistlichen, lautter 315 in ir gewissen dann der cristall. In den print das fürr des haÿligen gaistz, das ist die liebin, und in in ist die wonung der haÿligen driualtikaÿt, die da allweg zůnemend und nümer abnement.

Zům dritten so legt der haÿlig gaist den volkommen menschen für das dritt bůch, das ist den fürrin himel. [fol. 200 ${ }^{v}$ ] Darinn er sÿ zwaÿ ding lert, das ist die ${ }_{320}$ liebin und das schawen. Dann der himel brint also in der liebe so vast, das kain engel den andern laÿdiget. Also sol der volkommen mensch so vast enzündt sein in der lieb, das er kain menschen laidigen sol weder mit wortten noch mit wercken, und sol geleichmütiklichen dulden widerwärtige ding aller seiner veind. Auch ist der fürre himel liecht und hatt gott in im verschlossen. Also sol ${ }_{325}$ der volkomen mensch haben ain liechten wandel gegen seinen nachsten, nach dem und dann im ewangelÿ ist geschriben: Eüwer liecht sol also leüchten vor den menschen, das sÿ sechen eẅre gùtte werck und erwirdigent ewern vatter, der ist in himeln, verleich uns der allmächtig gott. Amen.

310-315 Da sprach der engel ... drÿualtikait (BGNS)] fehlt $M . \quad 310$ die, die $(B G N)]$ die $S$. 311 Randnotiz $A$ : Apostolus. endent $(B) G]$ erendend $N$, vendten $S$. send $(B G S)]$ sind $N$. ir das, das $(B G N)]$ fehlt $S . \quad 312$ nit $B G N]$ vnd nit $S . \quad$ erendent $B G(N)]$ endtet $S . \quad 313$ der engel $(B) G]$ er $N S$. 314 einwonung $(B G)$ ] einwanūg $N$, wonūg $S . \quad 315$ gůtten $B(G M S)$ ] gügn̄ $N$. 315f. lautter in ir gewissen $(B G) M(S)]$ jn ir gewissen leutter $N . \quad 316$ cristall. In den $(B) G(N S)$ ] cristallin den $A$, cristall in dem $M . \quad 317$ liebin $(B) G M N]$ lieb $S . \quad 318$ abnement $(B G)]$ ab nimpt $M$, ab $N S .319$ Zům dritten so $(B G M)] \mathrm{Zw}$ dē dritten mal so $N$, Zum tritten mal $S$. der haÿlig gaist $(B G M)$ ] er $N S . \quad$ menschen $(B G) M(S)]$ fehlt $N . \quad 320$ sÿ $(B G) M]$ fehlt $N S . \quad$ lert $(B) G(M)]$ lernt $N(S)$. 321 liebin $B G M N]$ lieb $S . \quad$ schawen $B G(M N)]$ beschawen $S$. Dann $B G(M N)]$ Wann $S . \quad$ liebe $G M(N S)]$ liebin $B . \quad 322$ enzündt $(B)]$ erzündt $(G) M(N S) . \quad 327$ dann im ewangelÿ $(G)$ ] dann jnn dem Ewangelio $B$, Dañ in ewangelÿ $M$, jm ewāgely $N$, jm Ewã $\tilde{a}^{\circ} S . \quad$ ist geschriben $(B G M)$ ] geschribñ ist ist $N$, geschriben stet $S$. sol also $B G M]$ sol $N$, das soll $S$. 328f. das sÿ ... in himeln $(B G M)]$ fehlt NS. 329 verleich ... gott $(B G M)]$ Das v $v^{s}$ leich vns got $N(S)$. Schreibernotizen: Amentellin $B$, Bitt gott für mich albegē $N$.

311f. Ir send ... erendent Gal 3,3. 327-329 Eüwer liecht ... in himeln Mt 5,16. 
